Hans-Jörg Schmid and Annette Mantlik

\title{
Entrenchment in Historical Corpora? Reconstructing Dead Authors' Minds from their Usage Profiles
}

\begin{abstract}
Data from eight historical corpora spanning the period between 1250 and 1871 are investigated with regard to occurrences of the ' $\mathrm{N}+\mathrm{BE}+$ that-construction' (as in my concern is that [...], the idea was that [...]). The formal, semantic, and pragmatic changes of this construction are described on the basis of 1,588 attestations retrieved from the corpora. Following this, the usage profiles of individual authors are examined. It is shown that even authors who are comparable in terms of period and genre show significant differences with regard to the frequency of use of the construction, collocational ranges and preferences, the use of semi-fixed lexical expressions manifesting the construction, as well as their functional preferences. These differences are interpreted from the perspective of the so-called 'Entrenchment-and-Conventionalization Model' (Schmid 2014a and 2015). It is argued that the usage profiles of individual authors can provide insights into the ways in which the construction under investigation was represented in these authors' minds, and that the observable collective long-term changes arise from the interaction of the cognitive processes in individual minds and the social processes taking place in the speech community.
\end{abstract}

Hans-Jörg Schmid, University of Munich

E-Mail: hans-joerg.schmid@anglistik.uni-muenchen.de

Annette Mantlik, Independent Scholar

E-Mail: annette-mantlik@gmx.de

\section{Introduction}

Language change is commonly conceived of as variation of the conventions of a language in time. It is generally considered to be a collective process taking place in speech communities and, as many linguists would insist on, a process that affects the structures and systems that make up language. While there is also considerable agreement that collective and systematic change is ultimately triggered and brought about by the linguistic activities of individual speakers, especially their innovations, this activity has largely remained outside the focus of the study of language change proper (Janda and Joseph 2003: 19). It is the study 
of generalizable structures, relations, and systems that is regarded as the main task of linguists rather than the description of the more or less idiosyncratic utterances or routines of individuals.

Of course certain social groups have been identified as being more or less likely to instigate language change. Likewise the individual styles of key literary figures have been analyzed and described (see, e.g., Craig 1992 and 2002; Taavitsainen 1995; Cannon 2004), and the impact of particularly prominent writers, such as Chaucer or Shakespeare, has been investigated with regard to the development of the lexicon (see, e.g., Horobin 2007; Craig 2011). But on the whole the work of individual authors has not been deemed worthy of serious, i.e. systematic, linguistic research. This is also confirmed in a study by Raumolin-Brunberg and Nurmi (2011), which is explicitly devoted to the role of the individual in language change: "The behaviour of the individual language user has not been among the key issues in the rapidly growing literature on grammaticalization. Nor has it been a popular topic in the general studies of language change" (Raumolin-Brunberg and Nurmi 2011: 251). The authors themselves investigate the use of the auxiliaries do, will, and would in the works of Sir Walter Raleigh, Philip Gawdy, and John Chamberlain and find that there is "a great deal of variation between individuals concerning their participation in ongoing linguistic changes" (Raumolin-Brunberg and Nurmi 2011:262).

Given the scarcity of precursors, the present study can be considered programmatic in nature. Following up on the lead by Raumolin-Brunberg and Nurmi (2011), we introduce a fresh framework for the interpretation of individual differences between the usage profiles of individual historical authors and for comparing them to each other and to the collective usage tendencies typical of their respective historical periods and genres. The findings will be interpreted in terms of types and degrees of entrenchment. The following argumentative steps motivate the rationale behind this study:

1. Collective processes on the macro-level of speech communities (conventionalization) have to be separated from cognitive processes on the micro-level of individual authors ${ }^{2}$ (entrenchment).

1 Individual authors are of course mentioned and quoted in many publications on language change and grammaticalization. Krug (2000), for example, explicitly includes the works of Daniel Defoe, Jane Austen, Charles Dickens, and Oscar Wilde and draws attention to special characteristics of their use of modal verbs. Overall, however, these references still are of an exemplary nature rather than providing systematic descriptions.

2 As this paper deals with texts written by historical authors, we will mainly use the term 'author' to refer to language producers. It is understood throughout that the theoretical background applies to both written and spoken forms of language production. 
2. The linguistic activities of individual authors contribute to shaping the collective conventions and the way they develop.

3. However, authors differ with regard to the extent to which and the ways in which they share and exploit the conventions and play a part in their dynamic development.

4. Historical corpus studies can help us understand not only the collective longterm trends but also the role played by individual authors.

5. The usage patterns and profiles of individual authors can provide an indication of how their uses of a given construction were 'represented' in their minds in terms of entrenched patterns of associations.

Essentially, then, this paper is an investigation into individual differences in usage patterns between authors. These are interpreted in terms of degrees and types of individual entrenchment, on the one hand, and in relation to collective conventions and their changes, on the other. We will investigate the use and development of only one construction consisting of an abstract noun followed by a form of the copula BE and a that-clause (see Section 2). Our study is meant to show that individual differences in entrenchment are a key to understanding constructional change specifically and language change in general.

The paper is structured as follows: in Section 2 we briefly introduce the construction under investigation. Section 3 is devoted to outlining the so-called 'Entrenchment-and-Conventionalization Model' (EC-Model; Schmid 2014a and 2015). This will serve as a framework which allows formulating specific predictions concerning degrees and types of entrenchment. In Section 4 we detail our corpus-based methods and material. Section 5 provides the results of the corpus study in terms of the general historical development of the target construction. This is followed (Section 6) by a quantitative and qualitative investigation of the usage profiles of individual authors and an interpretation in terms of the ECModel. Section 7 shows how the perspectives of entrenchment and conventionalization are linked.

\section{The Construction under Investigation}

As mentioned in the Introduction, the construction in focus, serving as a case study, has the form of an abstract noun, followed by a form of the copula BE, and a that-clause. We will refer to this construction as the ' $\mathrm{N}+\mathrm{BE}+$ that-construction'. The beginning of an entry in Samuel Pepys' famous diary can serve as an illustration: 
(1) 29th. [October 1664] All the talk is that De Ruyter is come over-land home with six or eight of his captaines to command here at home, [...]. (The Diary of Samuel Pepys, kept from January 1660 to May 1669, first published 1825)

In this example, the three parts of the ' $\mathrm{N}+\mathrm{BE}+$ that-construction' are represented by the talk, by is, and by that De Ruyter is come over-land respectively. Following common practice in Construction Grammar (cf., e.g., Traugott and Trousdale 2013: 16), we will consider Pepys' utterance as a so-called 'construct' and assume that the production of this construct is licenced by one or more 'constructions' which were represented in Pepys' mind and activated while adding the entry to his diary. Several constructions on different levels of specificity could have motivated the construct in example (1):

a. a very general, schematic construction of the type Det+N+copula+thatclause, whose meaning/function could be glossed as 'THING-concept (encoded by the noun) encapsulates proposition (encoded by the that-clause)';

b. a more specific but still schematic version, a sub-schema, which would take into account that talk is a linguistic noun; so the sub-schema would be Det $+\mathrm{N}_{\text {linguistic }}+$ copula + that-clause, associated with the more specific meaning 'speech-reporting noun encapsulates message';

c. a fixed expression, all the talk is that, i.e. a substantive, lexically filled construction, which could roughly be glossed as 'here is what people talk about these days'.

Which of these constructions motivated the use of (1) in Pepys' mind will of course remain in the domain of wild speculations. We believe, however, and will try to show in this paper, that the close scrutiny of data from historical corpora can indeed provide information on potential representations of constructions in the minds of historical authors or, couched in terms of the framework favoured here, on the relative degrees of entrenchment of different types of associations. It is to this framework that we will turn next.

3 We follow Langacker's (1987) ideas on word-classes and Schmid's (2000) concept of shell nouns here. 


\section{A Rough Sketch of the 'Entrenchment-and- Conventionalization Model'}

The theoretical framework informing this study is the so-called 'Entrenchmentand-Conventionalization Model', or EC-Model for short, developed by one of the authors over the past years (cf. Schmid 2013: 106-107, 2014a: 242-254, Schmid 2015). Essentially, the EC-Model tries to provide a coherent account of how grammar emerges from usage in social situations and keeps changing under the influence of usage. We will only give a very rough sketch of the model to leave sufficient space for the empirical concerns dominant here. A summary of the theoretical aspects can be found in Schmid (2015).

The major elements of the model are summarized in Figure 1 (taken from Schmid 2015). Usage and the four types of activities invariably involved in it sensory, motor, cognitive, and social activities - constitute the core of the model, thus marking the framework as belonging to the group of usage-based models. Its key assumption is that what we generally assume to be 'language' or 'the linguistic system' comes about and is continuously updated by the interaction of two types of processes: a limited set of cognitive processes operating in the minds of speakers, subsumed under the label 'entrenchment', and a limited set of sociopragmatic processes operating in communities, subsumed under the label 'conventionalization'. There are three entrenchment processes - association, routinization, and schematization - and four conventionalization processes - innovation, co-adaptation, diffusion, and normation. The interaction of entrenchment and conventionalization processes depends on usage and on the activities involved in usage, and is influenced by a (probably open-ended) set of cognitive, emotive-affective, pragmatic, and social forces.

Both entrenchment and conventionalization can only take place if similar usage activities of all four types are repeated in similar situations, serving similar functions. Neither routinization on the cognitive side, nor diffusion on the social one, is possible without repetition. As is well known (cf., e.g., Bybee 2003 and Diessel 2007 for a survey), the frequency of production of and exposure to repeated usage is among the key determinants of entrenchment, and the frequency of occurrence of utterance types among those of conventionalization.

Generally speaking, frequency affects entrenchment as follows: the productive or receptive processing of a given usage event will leave a memory trace of the neuronal and cognitive patterns of activation required for processing it. If the same or a similar usage event recurs several times, the pattern of activation will be strengthened and/or the commonalities of these usage events will be 'stored' in the form of a second-order 'representation', i.e. a schema. The first of these two 


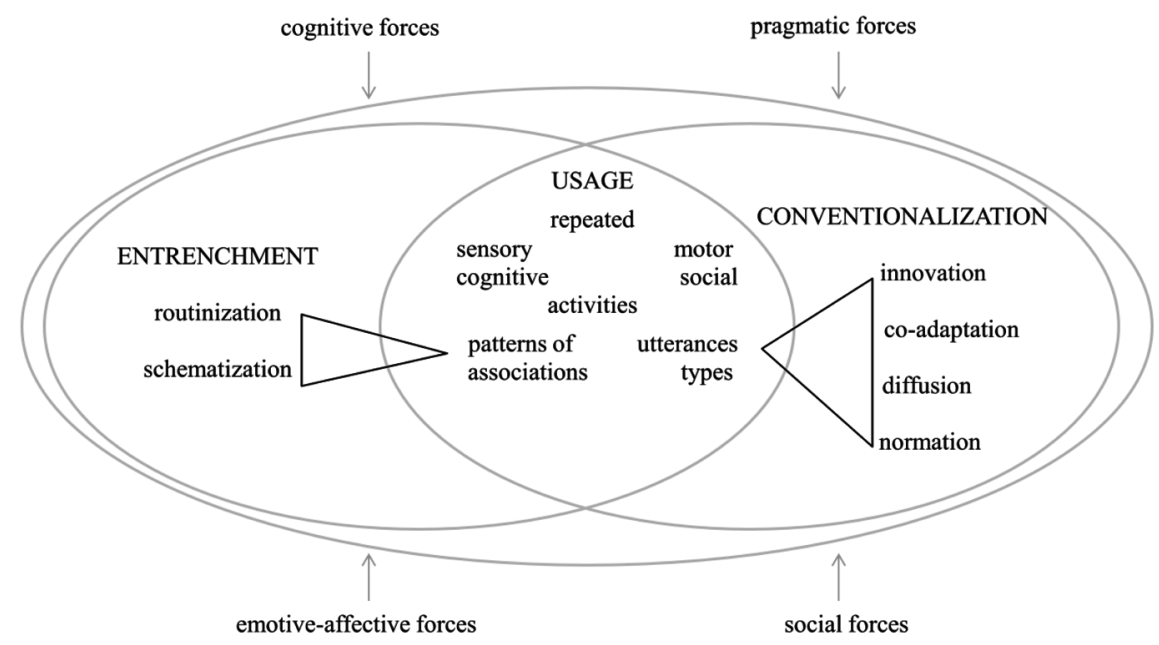

Figure 1: General outline of the EC-Model (taken from Schmid 2015)

processes is 'routinization', the second 'schematization'. In the EC-Model, both processes are considered to operate over patterns of different types of associations (see below). Note that the routinization part of entrenchment is essentially based on a form of associative or Hebbian learning, while schematization explicitly treated as an entrenchment process, too (cf. Schmid 2014b) - builds on the cognitive abilities of categorization and analogy.

It is of crucial importance to understand that different kinds of repetitions will have different effects on these entrenchment processes. In the EC-Model, this differentiation is implemented by a distinction between four types of associations - symbolic, pragmatic, syntagmatic, and paradigmatic associations - and by formulating systematic predictions concerning the ways in which different types of repetition affect the way in which the processes of routinization and schematization unfold.

Symbolic associations link the forms and meanings of linguistic elements in the minds of language users and thus afford the symbolic power of language. Entrenched symbolic associations are the cognitive and neuronal substrate of what we traditionally call 'linguistic signs', i.e. morphemes, lexemes, and grammatical constructions. Symbolic associations are routinized by the repeated processing of identical form-meaning pairings, triggered, for example, by exact repetitions of the same word-forms or fixed expressions. This type of entrenchment, cotext-free entrenchment, will facilitate later activation of the same symbolic association and reduce the amount of time and effort required to retrieve the form and meaning of an element in production and comprehension. 
Words and constructions that are ordered sequentially in a given utterance trigger syntagmatic associations. In language comprehension, syntagmatic associations are required for integrating meanings, while in production they are a major force in the sequential arrangements of the component parts of utterances. Syntagmatic associations link associations activated by the sequential processing of linguistic forms and meanings. They are strengthened by the repeated processing of sequences of identical or similar linguistic elements. This can result in a 'chunking' of the given sequence and the emergence of a symbolic association connecting the whole chunked form to one non-compositional meaning, accompanied by a reduction of the strength of the symbolic associations of its parts. Valency patterns, collostructions, collocations, idioms, and other types of co-occurrence patterns that allow language users to predict what will come next rely on more or less deeply routinized syntagmatic associations. The routinization of syntagmatic associations is referred to as cotextual entrenchment.

Paradigmatic associations link associations triggered by processing the forms or meanings of linguistic elements to alternative associations that are potentially co-activated. Paradigmatic associations thus activate what could have been said or meant instead of what was said or meant. Paradigmatic associations strongly interact with pragmatic and especially syntagmatic associations; in fact, they depend on them because paradigmatic alternatives only arise within a given linguistic cotext and situational context. Paradigmatic associations are thus essentially probabilistic expectations that depend on and are created by syntagmatic and/or pragmatic associations. Paradigmatic associations are routinized by the repetition of different elements in an identical or similar cotextual or contextual environment. Thus, paradigmatic associations connect the lexemes that can fill the variable slot in a schematic or partly schematic construction, for instance the nouns that can be inserted in the nominal slot in the ' $\mathrm{N}+\mathrm{BE}+$ thatconstruction'. Paradigmatic associations also link the constructions that are potentially activated by pragmatic associations to recurrent types of communicative events, for instance hello, hi, hi there, good afternoon in a greeting situation. The cognitive process of analogy plays a key role in this routinization process, identifying the shared role elements play in a given cotext or context. Crucially, the paradigmatic associations between elements competing for a given slot in a grammatical environment and the syntagmatic or pragmatic associations creating this environment work together in the process of schematization. Syntagmatic associations are responsible for establishing the links between sequentially arranged elements or variable slots, e.g. the noun slot, the copula slot, and that in the 'N+BE+that-construction', paradigmatic ones for the links between the elements competing for occurrence in variable slots, i.e. the nouns and the different 
forms of the copula. The schemas resulting from this process are strengthened by the repeated processing of different elements instantiating the same schemas.

Finally, pragmatic associations connect symbolic, syntagmatic, and paradigmatic associations and their component parts to mental states activated by perceptual input from the usage event and by subsequent spreading activation and inferential mechanisms. They are regarded as encompassing information about the physical (time, place, props, etc.) and social situation (participants and their social roles), about the larger preceding linguistic cotext (what was said or written before the current utterance), and about the pragmatic acts, moves, and intentions of discourse participants, including inferential mechanisms like implicatures or irony. Pragmatic associations become routinized by the repeated processing of identical or similar linguistic elements under similar contextual circumstances, resulting in contextual entrenchment. Faced with a specific situation, contextually more entrenched elements are more likely to be activated than elements that are not pragmatically associated, even if the latter show a higher degree of cotext-free entrenchment.

As pointed out before, a more detailed description of the EC-Model can be found in the publications mentioned above, especially Schmid (2015). The ways in which the model can be operationalized for the investigation of usage patterns in corpora will be formulated in Section 5. Before, however, we will introduce the material used in this study and explain how it was collected and analyzed.

\section{Material and Methods}

Several historical corpora were used to retrieve authentic attestations of the 'N+BE+that-construction'. The material ranges from 1250 up to the arbitrarily chosen point of 1871 (the publication of George Eliot's novel Middlemarch). The resulting body of data was used firstly to understand how the construction evolved and developed during this period, i.e. for the study of its conventionalization, and secondly, this macro-development and its stages serve as a benchmark against which data from individual authors can be assessed in terms of entrenchment. The eight corpora listed in Table 1 were accessed online or retrieved from the Internet. In addition to listing the sources, Table 1 renders the numbers of words, the text types contained in the corpora, the time span covered by the sources, as well as the numbers of tokens of the 'N+BE+that-construction' they yielded. 
Table 1: Data acquisition: eight corpora accessed online or retrieved from the Internet ${ }^{4}$

\begin{tabular}{lrllr}
\hline Corpus & $\begin{array}{l}\text { Approx. Number } \\
\text { of Words }\end{array}$ & Text Types & Time & $\begin{array}{l}\text { Number of } \\
\text { Tokens }\end{array}$ \\
\hline Gutenberg & $18,500,000$ & $\begin{array}{l}\text { Fiction, Essays, } \\
\text { Chronicles }\end{array}$ & $1250-1871$ & 1,039 \\
\hline OED3 & $20,000,000$ (est.) & Mixed & $1250-1871$ & 194 \\
\hline Helsinki & $1,500,000$ & Mixed & $730-1710$ & 13 \\
\hline Old Bailey & $17,000,000$ & Court Proceedings & $1720-1871$ & 153 \\
\hline Paston & 200,000 & Letters & $1422-1509$ & 9 \\
\hline PCEEC & $2,200,000$ & Letters & c. $1410-1695$ & 140 \\
\hline Shakespeare & 900,000 & Drama, Poetry & $1590-1612$ & 17 \\
\hline Jane Austen's & 140,000 & Letters & $1796-1817$ & 23 \\
Letters & & & & \\
\hline
\end{tabular}

Total 1,588

The bulk of the raw text material for this study was downloaded from the Project Gutenberg website offering novels, essays, treatises, chronicles, and other texts. The work of 83 authors spanning the period from 1250 to 1871 is represented in the version of the Gutenberg sub-corpus used for this study. Another important contribution to our material is made by the quotation database of the OED3, which contains an estimated 20 million words in the quotations from that period (Rohdenburg 2013: 145). The Old Bailey corpus (see Huber 2007) collects the court proceedings of the Old Bailey court in London from 1720 to 1913. In addition, the classic historical corpora of the English language - the Helsinki Corpus, the Paston letter corpus, the Parsed Corpus of Early English Correspondence (PCEEC), the Online Shakespeare concordance, and the collection of Jane Austen's letters available at the University of Oxford Text Archive, were all used for data retrieval. As Table 1 shows, roughly two thirds of the material comes from the Gutenberg collection; the rest is scattered across the other corpora, with OED3, the Old Bailey corpus and PCEEC contributing quite substantial numbers of observations (194, 153, and 140 attestations respectively). The data was retrieved from these sources by means of different search queries adapted

4 Detailed references to the corpora can be found at the end of the paper. 
to the corpus in question and its query language. The results of all queries were subjected to manual post-processing, leaving us with the 1,588 attestations of the 'N+BE+that-construction' from 139 known authors plus numerous more from the Old Bailey corpus and other sources. The calculation of relative, or normalized, frequencies per author is only possible for the data from Project Gutenberg, the complete works of Shakespeare and Jane Austen's letters because total numbers of words are known for these sources. The data from the Helsinki Corpus and the Old Bailey corpus do not allow for the calculation of authorrelated relative frequencies since data on overall amounts of words by authors are not available.

All 1,588 examples were coded in terms of the lexical, semantic, textual, pragmatic, and user-related variables listed in Table 2: the variables source, AUTHOR, and DATE are self-explanatory. All noun tokens were LEMMATIZED and classified on two levels of granularity according to their SEMANTIC TYPE, following the categories introduced by Schmid (2000). TEXT TYPEs were also classified in broad terms and so were the PRAGMATIC FUnCTIONS of the utterance as a whole. In addition, it was recorded whether the particular token was a hapax ( \pm HAPAX) within the scope of our dataset and whether the noun type is still used in the 'N+BE+that-construction' in Present-Day English ( \pm OBsolete). Obsolescence was operationalized by checking the nouns against Schmid's (2000) inventory of nouns occurring in the 'N+BE+that-construction' in Present-Day English. ${ }^{5}$

Table 2: Data coding: variables and values

\begin{tabular}{ll}
\hline Variable & Values \\
\hline SOURCE & name of corpus (Gutenberg, PCEEC, etc.) \\
\hline AUTHOR & author name \\
\hline DATE & year of publication of original source \\
\hline $\begin{array}{l}\text { NOUN LEMMATIZED } \\
\text { (normalization of } \\
\text { Spelling variants) }\end{array}$ & $\begin{array}{l}\text { noun lemmas, e.g. ISSUE for issue and yssue or INTENT for intent and } \\
\text { entent }\end{array}$ \\
\hline
\end{tabular}

5 In addition, all 1,588 tokens were analyzed and coded with regard to the type of determiner preceding the noun (e.g. article, possessive pronoun, demonstrative pronoun), the tense of the copula, and whether or not there were words intervening between the noun and the copula (e.g the insertion of my ring in the example and the virtue of my ring is that [...] found in Thomas Malory's Le Morte d'Arthur, 1485). Since these variables are not discussed in this paper, however, we will not pursue them any further. 


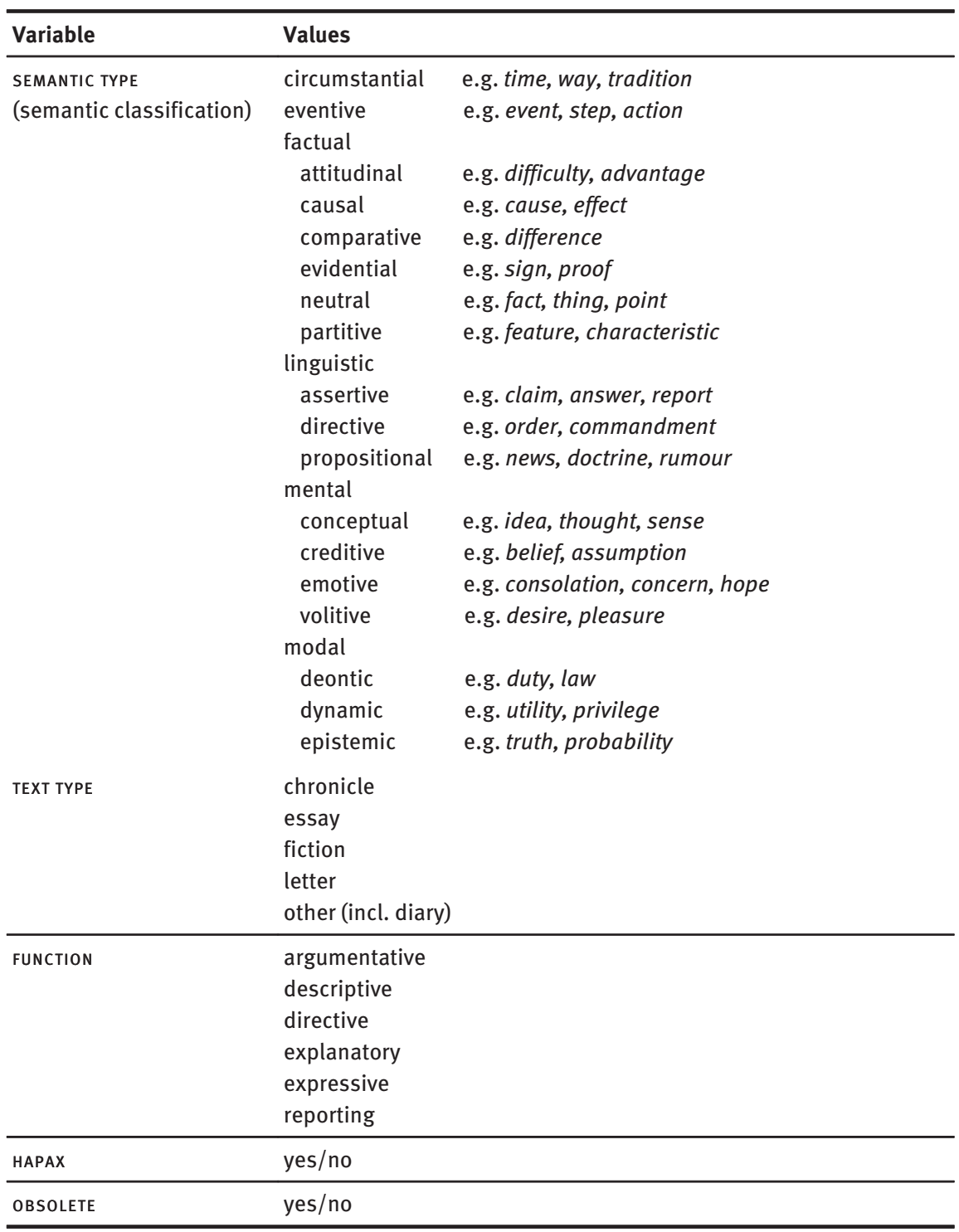




\section{Findings I: The Historical Development of the 'N+BE+that-Construction'}

We will provide the following pieces of information in order to describe the general historical development of the ' $\mathrm{N}+\mathrm{BE}+$ that-construction': the earliest known attestation (Section 5.1); formal (5.2), semantic (5.3), and pragmatic changes (5.4); changes concerning usage frequencies (5.5); and sources of innovation (5.6). More details using a complementary method of analysis can be found in Mantlik (2011).

\subsection{First Known Attestation}

The earliest attestation of the 'N+BE+that-construction' in our database was found in the Helsinki Corpus and comes originally from The Appeal of Thomas Usk against John Northampton written in 1384:

(2) And, truly, the ful entent was that al the ordinances that wer ordeyned in hys tym [...]. (1384, Helsinki Corpus, The Appeal of Thomas Usk against John Northampton)

The year 1384 is thus the terminus ad quem - the time from when on we can be certain that the construction was actually used (cf. Mantlik 2011: 11).

As far as the origin of the construction in English is concerned, we assume that we are dealing with a case of structural borrowing from Romance (Mantlik 2011: 174, 195). Cognate constructions are attested in both Latin and Old French (cf. Mantlik 2011: 173-195). The heavy preponderance of nouns of Romance origin in the construction also points in this direction (cf. the examples listed in Table 2 above; see Mantlik 2013 on the etymology of shell nouns, and Mantlik 2011 for a detailed discussion of the predominant origins of the nouns occurring in shellnoun-constructions). Very early nouns of this type are garnison (1386, Chaucer), proclamation (1387, unknown author quoted in OED3), counsel (1393, Gower), medicine (1397, Trevisa), and statute (1425, Mandeville). Nevertheless, some of the nouns observed to occur early in the construction are of Germanic origin, among them mete (1430, Chaucer, see example 5 below), will (1430, Chaucer, example 4), thing (1430, Chaucer), kind (1425, Mandeville, see example 8), and sooth (1397, Trevisa, example 10; also used as many as five times by Chaucer, 1430). 


\subsection{Formal Changes}

Overall, the formal properties of the inflexible parts of the ' $\mathrm{N}+\mathrm{BE}+$ that-construction' have remained astonishingly stable. Two aspects seem worth reporting. Firstly, the insertion of a comma between the copula and that remained common, though unsystematic, until the eighteenth century. ${ }^{6}$ Sporadic commas are found as late as 1871, in George Eliot's Middlemarch, at least in the edition downloaded from Project Gutenberg. Secondly, the omission of the complementizer that starts in the early seventeenth century with the noun truth. ${ }^{7}$ The first attestation of the zero variant was found in The Proficiency and Advancement of Learning by Francis Bacon published in 1605.

(3) [...] and so goeth on in an irony. But the truth is, they be not the highest instances that give the [...]. (1605, Francis Bacon, The Proficiency and Advancement of Learning)

It took considerable time until other nouns, the next one being fact, were also used with complementizer omission and until the zero-complementizer variant began to occur with noteworthy frequencies (cf. Mantlik and Schmid forthcoming for more details).

A key indicator of the development of the construction is the question which nouns were used in the nominal slot. While details about the types of nouns will be discussed in the next section devoted to semantic changes (5.3), information on the quantitative aspects is better placed here. Overall, the 1,588 tokens in our database represent 293 types. As many as 133 of these are hapax legomena in our data. The introduction of new nouns in the variable slot - which are hapaxes by definition - reflects the vitality of the schematic construction and can be interpreted as a sign of its continuing productivity (cf. Hilpert 2013: 127-133). Remarkably, this productivity remains high throughout the whole period of our investigation. This is demonstrated by Figure 2, which shows the number of hapaxes per 50-year period. ${ }^{8}$ The figure indicates that new collocates which were not repeated (at least until 1871) continue to be introduced.

6 To what extent the use of commas was influenced by editorial practices and decisions was not investigated.

7 As regards complementizer omission with verbs, Rissanen (1991) found a steady relative increase of zero complementizers from 14 per cent between 1350 and 1420 to almost 70 per cent in the period between 1640 and 1720. Finegan and Biber (1995) showed that this development is also subject to register variation.

8 The division of the data into 50-year periods is potentially problematic because it may be too coarse and runs the risk of introducing boundaries that are not motivated by the structure of the 


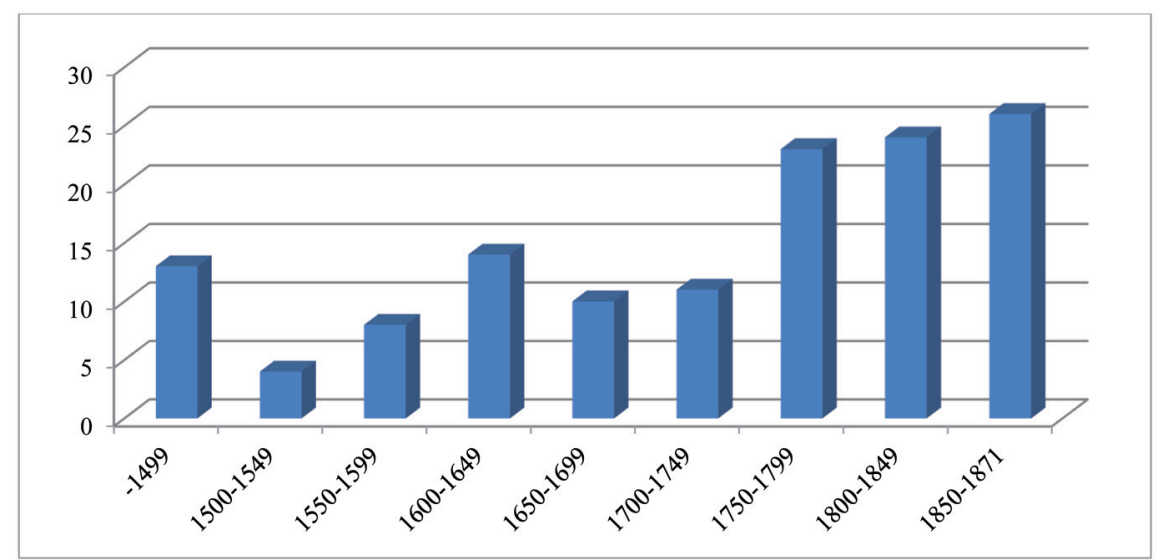

Figure 2: Absolute number of hapaxes in the dataset per 50-year period

The impression that the nominal slot of the construction is subject to considerable change is supported additionally by the large number of nouns in the dataset which are no longer used in the construction in Present-Day English. As many as 160 obsolete types are attested, ${ }^{9}$ which corresponds to a proportion of 55 per cent of the 293 types found altogether. As can be expected, the relative number of tokens of obsolete types generally decreases over time. However, though quite close to Present-Day English, the final period from 1850 to 1871 still musters as many as 45 tokens of nouns that no longer occur in the construction today, among them meaning, purpose, sense, substance, and wonder.

Overall the findings on hapaxes and obsolete types clearly show that the changes in the collocational range of the nouns occurring in the construction are considerable, reflecting a dynamic development which seems to be fairly typical of language change in general.

data. In order to avoid these problems, we applied Gries and Hilpert's (2012) method of variability-based neighbour clustering, which allows for a bottom-up periodization of the data. However, for the present data the method turned out to be too strongly influenced by the large number of outliers (see Section 6.2 below) and suggested a division into no more than three periods spanning the years 1377-1566, 1567-1791, and 1792-1871 respectively. The method was then improved by including the nominal variables NOUN TYPE and FUNCTION (see Hilpert 2013: 38-42). This reduced the effect of outliers in terms of sheer frequency, but did not yield a more fine-grained division. We therefore decided that for the purposes of the present paper, 50-year periods would be a reasonable choice after all.

9 Obsolete types, i.e. nouns that are no longer used in the 'N+BE+that-construction', which occur more than five times in our data are account, case, counsel, end, event, intent, law, matter, meaning, mind, object, pleasure, presumption, report, sooth, substance, talk, trust, will, and wonder. 


\subsection{Semantic Changes}

The changes of the collocational range also affect the semantic development of the construction, of course. While we cannot go into detail here, the most remarkable semantic change is demonstrated by the line charts provided in Figures 3 and 4. Both figures render the relative frequencies of tokens of different classes of nouns per 50-year period. ${ }^{10}$ Figure 3 collects five classes whose relative frequencies decrease, Figure 4 four classes whose share of the total data per period increases.

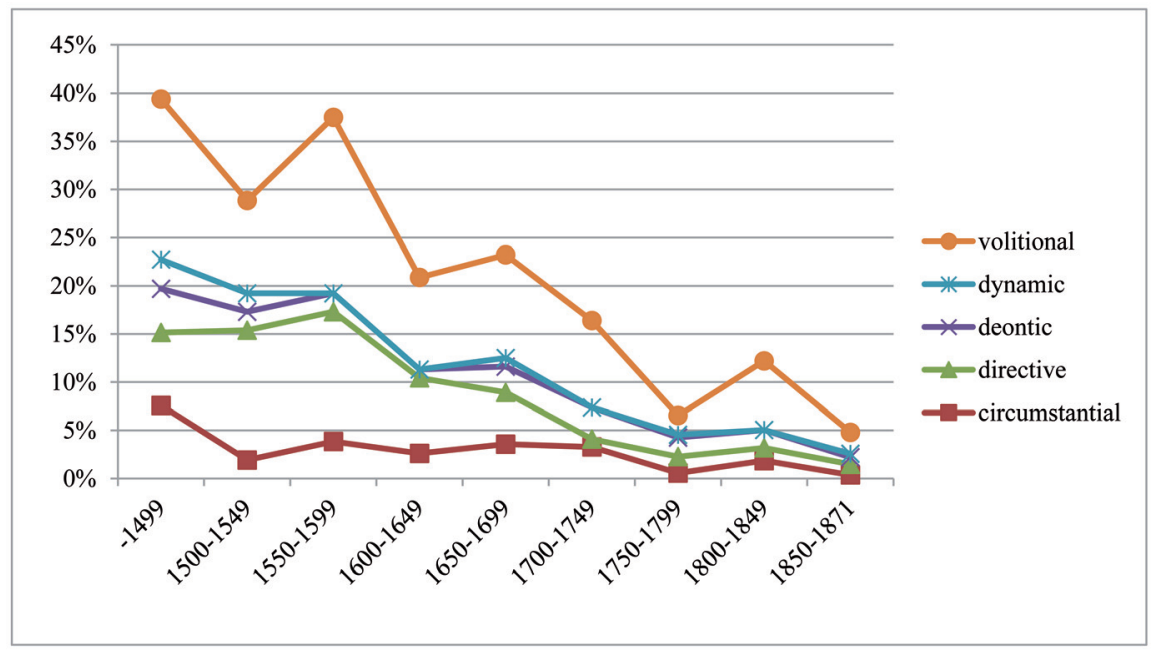

Figure 3: Decrease in relative frequency of nouns expressing volition, dynamic and deontic modality, directive illocutions, and circumstance

10 We refrain from discussing the statistical significance of the trends that can be gleaned from the two figures because they are co-determined by other variables, most notably by the highly variable availability of sources in different periods and their genres and text types. The overall trend seems strong enough. Given the comparatively low prominence of this aspect in the present paper, we do not think that it is necessary to subject the data to multivariate statistics such as regression models. 


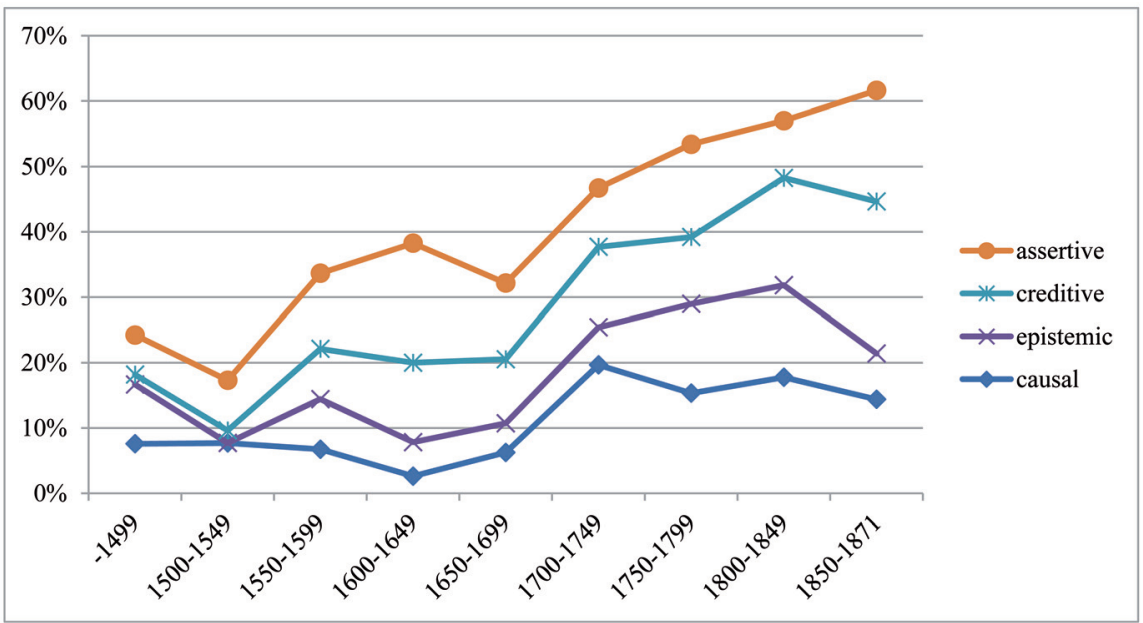

Figure 4: Increase in relative frequency of nouns expressing assertion, belief, fact, and cause

The types of nouns collected in Figure 4 share semantic components related to actions and events: volition (see example 4), dynamic modality (5), obligation (6), giving orders (7), and circumstance (8):

(4) volitional: The wyl of crist was that she sholde abyde. (Chaucer, Canterbury Tales, 1430)

(5) dynamic: My mete ['means of support of strength', OED3, s.v. mete] is that I do the will of him that sente me. (Wycliffe Bible, John 4:34, 1384, OED3)

(6) deontic: The lawe of Medis and Persis is that eche decree whiche the kyng ordeyneth be not leeful for to be chaungid. (Wycliffe Bible, Daniel 6:15, 1384, OED3)

(7) directive: Our request is, that you would by the bearer of these presents, [...]. (Hakluyt, The Principal Navigations, Voyages, Traffiques and Discoveries of the English Nation, Vol. 1, 1598)

(8) circumstantial: The kind of the mors is that they wole leefe noothing empty besides hem. (Mandeville, Mandeville's Travels, around 1425, OED3)

As shown in Schmid (2000), in Present-Day English all these nouns are much more likely to be complemented by to-infinitives than by that-clauses. In contrast, the classes of nouns brought together in Figure 4 are related to abstract states and relations, the epistemic domain, and linguistic statements rather than actions: states of believing (see example 9), epistemic modality (10), causal relations (11), and assertive illocutions (12).

(9) creditive: My judgment is, that they ought all to be despised. (Bacon, Essays of Francis Bacon, 1627) 
(10) epistemic: [...] but the sooth ['truth'] is, that they were strong hores [...]. (Trevisa, De Proprietatibus Rerum, 1397)

(11) causal: The cause is that they labour do despyse. (Brand, The Ship of Fools, 1494)

(12) assertive: And your reporte is that you haue done it with my consent. (PCEEC, 1573)

Figures 3 and 4 reflect a trend in the history of English that resulted in a semantic distinction between verbs and nouns preferring infinitival complements and those usually taking that-clauses (cf., e.g., Givón 1990: 517-561). The former cluster, corresponding to Givón's "manipulative verbs", is associated with actions and events taking place in the real world, as well as obligations, wishes, aims, etc., the latter, corresponding to Givón's "cognition-utterance verbs", with ideas, thoughts, beliefs, and abstract relations such as causation. The two figures show that nouns belonging to the event-related group used to be complemented by that-clauses in the early period, but - as a comparison with their use in PresentDay English indicates - were later 'absorbed' by the infinitive. The increase in the proportion of cognition-utterance nouns is caused by larger numbers of both types and tokens manifesting this semantic cluster.

\subsection{Pragmatic Changes}

The main parameter of pragmatic change is the function of the utterance containing a given $\mathrm{N}+\mathrm{BE}+$ that-construct. The data represented in Figure 5 show trends which partly correlate with the semantic development: first, the explanatory function is strong in the very first stage following the introduction of the construction, but begins to lose ground soon. This function is prominent in examples 5, 6, 8,11 and 12. Second, being represented quite strongly in the data from the sixteenth century, the directive function, illustrated in example 7 , virtually becomes extinct at the beginning of the eighteenth century, coinciding with the decline of uses of the ' $\mathrm{N}+\mathrm{BE}+$ that-construction' for the cluster of nouns collected in Figure 3. Third, the opinative (cf. example 9) and especially the reporting functions (cf. example 12) gain in relative importance, which is matched by the increase in the use of creditive and assertive nouns shown in Figure 4.

As far as text types are concerned, we have only investigated the data from those sources whose extent - in numbers of words - we could identify with sufficient reliability for calculating normalized frequencies of occurrence. This part of the data yielded the relative frequencies rendered in Figure 6. The 'personal' genres biography, letter, and diary reach higher relative scores than essays and chronicles, followed by prose fiction (novel, romance, satire) and more formally restricted forms of literary writing (drama, poem). Overall, less formal 


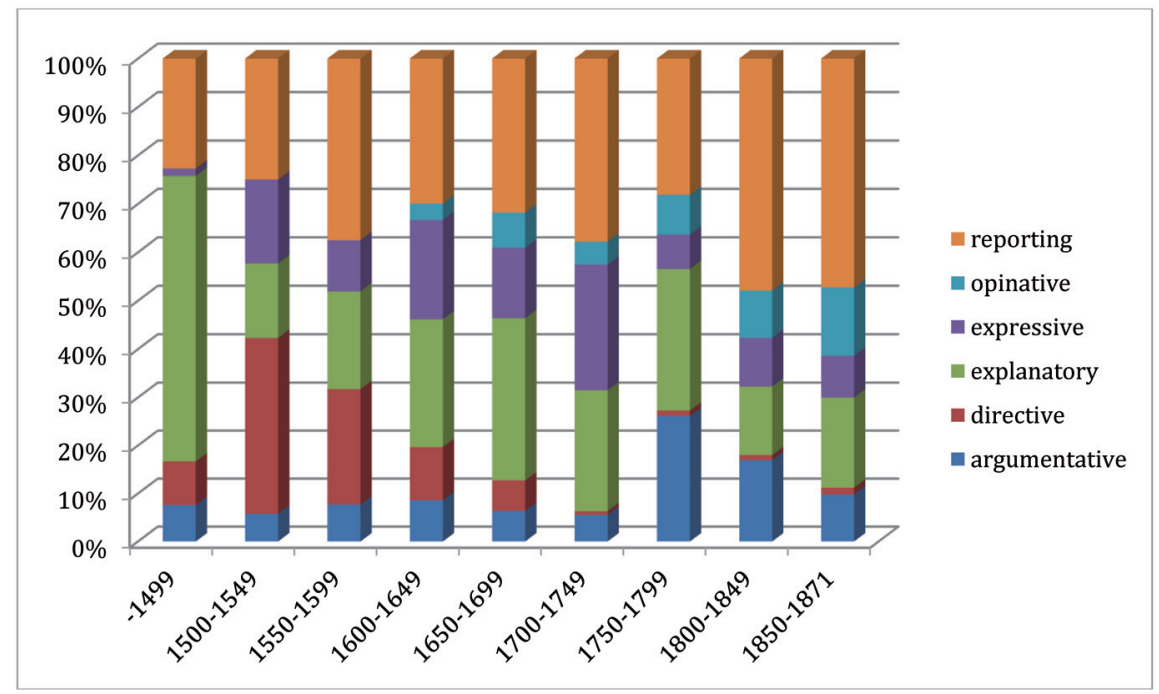

Figure 5: Changes in distribution across functions (four additional tokens which serve the descriptive function are omitted in the figure for the sake of clarity)

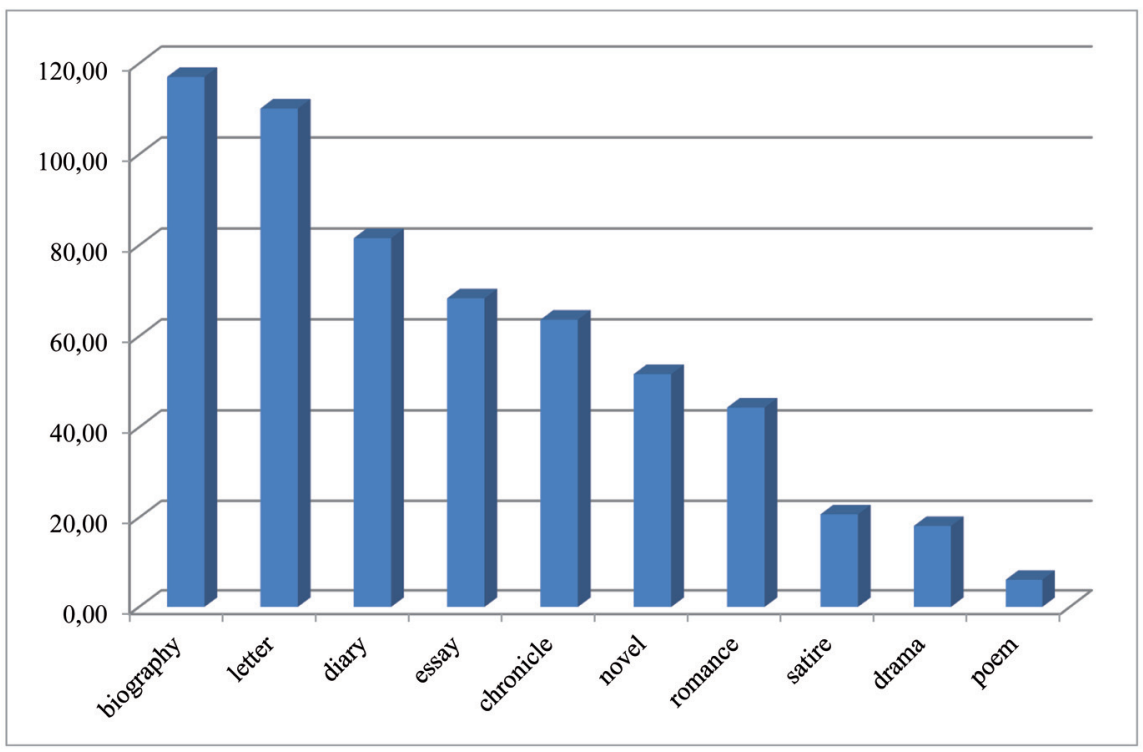

Figure 6: Frequency per million words in different genres $(n=1069)$ 
genres seem to provide a better habitat for the construction to thrive in than more formal ones. Given notorious problems with genre classifications across centuries, and given the influence of other variables such as topic, style, and of course time, the reliability of these findings should not be overestimated, however.

\subsection{Changes in Frequency}

Figure 7 provides the relative frequencies per million words per 50-year period. Not surprisingly, the construction is used with increasing frequency, with a noticeable upward spike found towards the end of the eighteenth century. Since the availability of sources that could be added to our convenience sample and the genres of these sources of course influence the overall development in terms of frequency of use of the ' $\mathrm{N}+\mathrm{BE}+$ that-construction', we refrain from venturing an interpretation of this finding. The main purpose of Figure 7 is to serve as a backdrop for the more fine-grained analysis reported in Section 6.2 below.

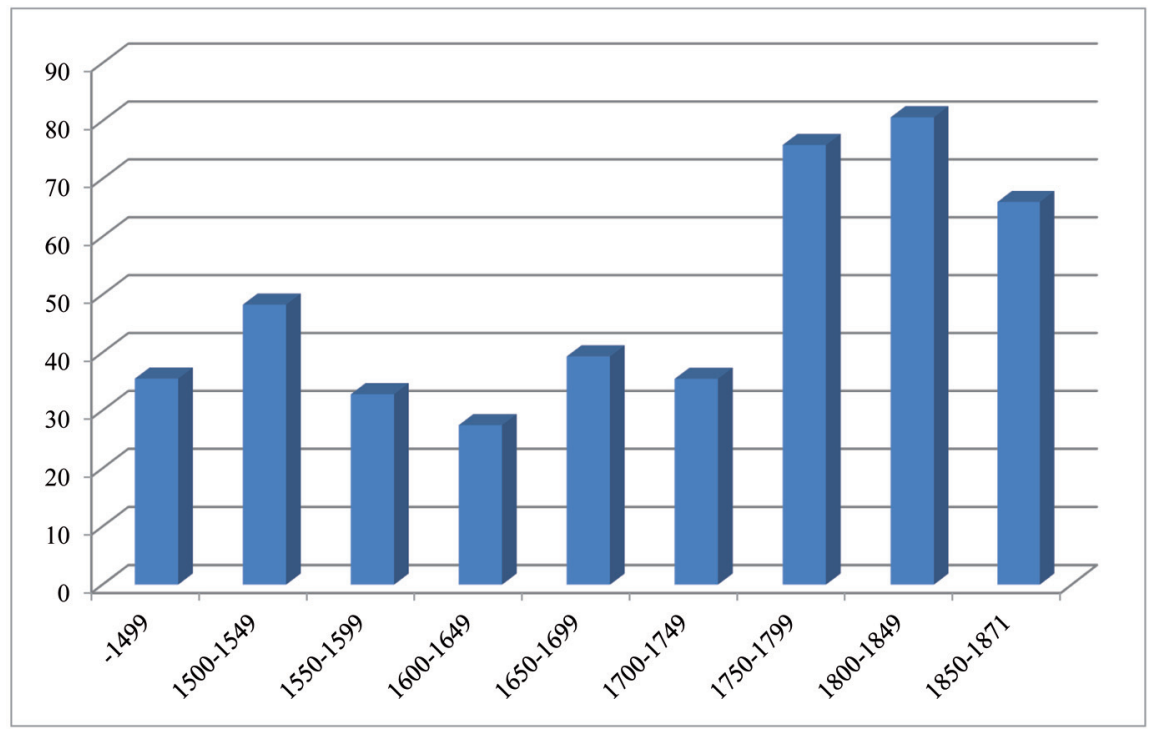

Figure 7: Relative frequency per million words per 50-year period 


\subsection{Locus of Innovation}

Innovation regarding the use of the target construction will be described here in terms of extensions of the collocational range by introducing nouns not attested before. Table 3 provides the dates and sources of the earliest attestations of selected nouns. Anticipating the author-related perspective that will dominate in Section 6, the names of innovators - always relative to our database - are listed as well, if known. To give a more systematic presentation of the data is neither required nor reasonable, as it would again mainly be a reflection of the data situation. The main point to be gleaned from Table 3 is that it does not reveal a consistent trend concerning the question whether the semantic and pragmatic changes described in the previous sections are changes 'from above', as would be indicated by a preponderance of innovations in 'learned' writing, or 'from below', as suggested by innovations in personal letters or direct speech in fiction, especially when attributed to figures of low social standing. The preponderance of nouns of Romance origin already mentioned above speaks in favour of the idea that innovations come 'from above' rather than 'below'.

Table 3: Dates and sources of first attestations of selected nouns in the ' $\mathrm{N}+\mathrm{BE}+$ that-construction'

\begin{tabular}{llll}
\hline Noun & Date & Type of Source & Author \\
\hline condition & 1430 & fiction & Chaucer \\
\hline meaning & 1430 & fiction & Chaucer \\
\hline thing & 1430 & fiction & Chaucer \\
\hline answer & 1469 & letter & \\
\hline opinion & 1470 & letter & Caxton \\
\hline cause & 1474 & essay & \\
\hline advice & 1517 & letter & Hall \\
\hline truth & 1519 & letter & Painter \\
\hline desire & 1548 & fiction & \\
\hline conclusion & 1567 & fiction & \\
\hline charge & 1574 & letter & \\
\hline wish & 1585 & letter & \\
\hline reason & 1589 & letter & \\
\hline difference & 1591 & letter & \\
\hline
\end{tabular}




\begin{tabular}{llll}
\hline Noun & Date & Type of Source & Author \\
\hline news & 1592 & fiction & Shakespeare \\
\hline comfort & 1595 & fiction & Shakespeare \\
\hline hope & 1604 & letter & \\
\hline belief & 1651 & essay & Hobbes \\
\hline fact & 1669 & diary & Pepys \\
\hline misfortune & 1677 & letter & \\
\hline consequence & 1709 & essay & Berkeley \\
\hline idea & 1739 & essay & Hume \\
\hline result & 1744 & essay & Haywood \\
\hline substance & 1756 & essay & Burke \\
\hline probability & 1762 & essay & Burke \\
\hline agreement & 1790 & essay & Burke \\
\hline case & 1791 & essay & Paine \\
\hline plan & 1796 & fiction & Austen \\
\hline thought & 1848 & fiction & Thackeray \\
\hline
\end{tabular}

As the table indicates, a number of nouns are first attested in letters and then found to occur in published sources. Essays are a source of more formal types of nouns used mainly with argumentative and explanatory functions. Fiction contains a variety of innovations in the construction, ranging from linguistic, over factual, to modal nouns.

Summing up our bird's eye view of the diachronic development of the 'N+BE +that-construction', we can recapitulate that the construction has been subject to considerable change with regard to frequency, collocational range, meaning, and function.

\section{Findings II: Usage Profiles of Individual Authors Interpreted in Terms of Entrenchment}

Keeping the findings reported in the previous section in mind, we will now proceed to a comparison of the usage profiles of individual authors. Two goals motivate this endeavour: we want to show, firstly, that individual authors participate in and contribute to the collective development of the construction in very 
different ways, and secondly, that the usage profiles of individual authors provide clues as to the way in which the construction may have been entrenched in their minds. We will begin by spelling out the rationale underlying our analysis and then report findings pertaining to the different types of entrenchment processes and associations discussed in Section 3.

\subsection{Assumptions and Predictions}

The basic assumption behind this investigation is that different degrees of entrenchment (in terms of routinization) and different types of entrenchment (in terms of types of associations and levels of schematization) correlate with and are manifested in the usage patterns of individual authors. This in turn rests on the conjecture that strongly entrenched patterns of associations are more likely to be activated than less strongly entrenched ones, and that therefore frequencies of patterns of utterances reflect patterns of entrenchment. For example, if, as will be shown, Samuel Pepys stands out by repeated uses of the expressions all the talk is that and all the news is that, then this can be interpreted as indicating that these expressions were licenced by strong syntagmatic associations resulting in a chunk-like representation of these sequences in his mind.

By reversing the perspective of the EC-framework outlined in Section 3, these assumptions can be translated into the following predictions:

1. General prediction: the usage patterns of comparable individual authors will differ. These differences can be interpreted in terms of different degrees and types of entrenchment.

2. Specific predictions:

a. Authors will differ regarding the relative frequencies with which they use the ' $\mathrm{N}+\mathrm{BE}+$ that-construction'. These differences reflect different strengths of symbolic associations linking the form(s) and meaning(s) of the construction.

b. Authors will differ regarding the preferences and ranges of nouns used in the construction, and the paradigmatic relations between these nouns, and with regard to their inclination to use new nouns (innovations). These differences reflect different strengths of paradigmatic associations and different types of schemas.

c. Authors will differ regarding their usage of semi-fixed strings. These differences reflect different strengths of syntagmatic associations between the component parts in their minds. 
d. Authors will differ regarding the functions with which and the contexts and cotexts in which they use the construction. These differences reflect different strengths of pragmatic associations.

These predictions will be taken up in the following sections.

\subsection{Frequency of Usage}

To provide a first overview, Figure 8 plots the relative frequencies of the construction per work. Since the data represented in Figure 7 showed an average frequency of around 30 tokens of the ' $\mathrm{N}+\mathrm{BE}+$ that-construction' per million words before 1750, which means that one can expect one occurrence in approximately 30,000 words, the plot includes only those works that contain more than 30,000 words. Zero attestations in texts that are shorter than 30,000 words are not informative.

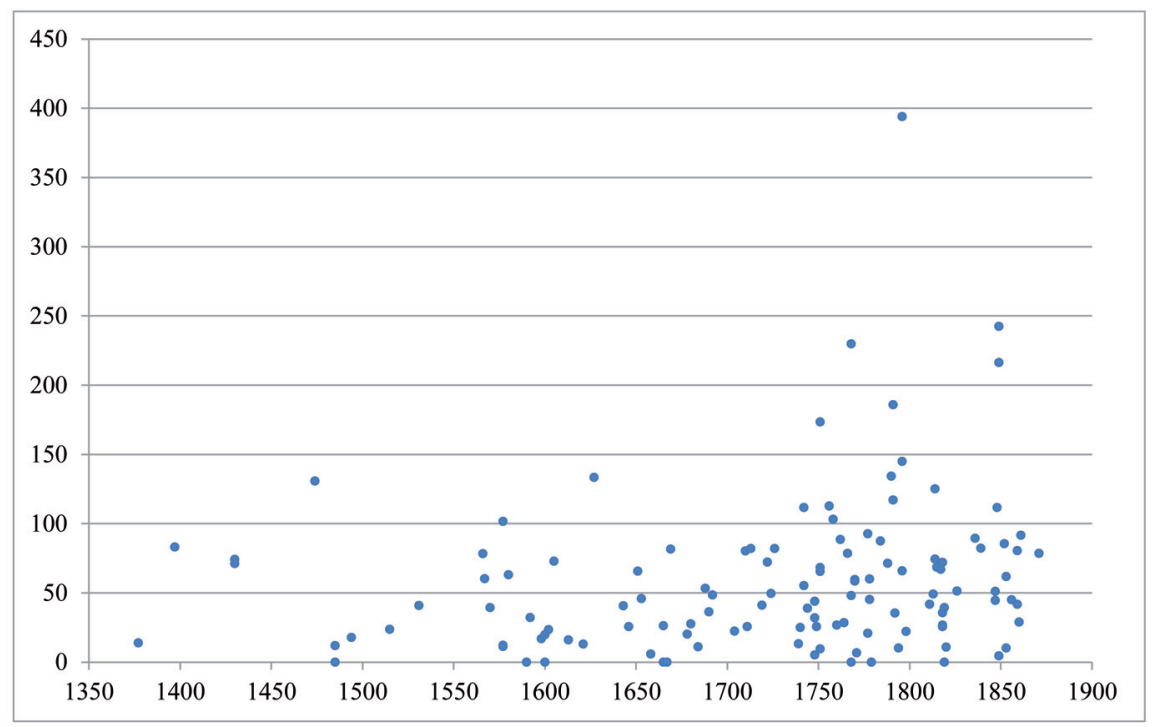

Figure 8: Frequencies of occurrence per million words per source (only works containing more than 30,000 words)

The plot confirms the overall trend to be observed in Figure 7. It also shows, however, that as expected (see note 8 above), reporting average frequencies per 50 -year period runs the risk of glossing over quite substantial authorial differences. In fact, there is considerable variation between the sources, with several of 
them not containing a single attestation of the construction on the one extreme, and an outlier of almost 400 occurrences per million words - Thomas Paine's The Age of Reason (1796), boasting as many as 26 occurrences in 65,986 words - on the other. Small or zero scores at the low end of the scale only seem remarkable if they diverge significantly from the general trend of the period, and if this happens in spite of a large output. Cases in point are Thomas Malory, who produces a mere two instances in the 352,791 words making up the two volumes of Le Morte d'Arthur (1485); John Milton with not a single one in almost 80,000 words in Paradise Lost (1667); and Tobias Smollett with only one occurrence each in his two hefty volumes The Adventures of Peregrine Pickle (1751; 317,864 words) and The Expedition of Humphrey Clinker (1771; 150,473 words). While nobody would conclude that Milton did not have command of the ' $\mathrm{N}+\mathrm{BE}+$ that-construction', these very low frequencies of usage may indicate that the construction was not sufficiently deeply entrenched for it to be activated in language production more often, at least as far as the genre represented by Paradise Lost is concerned (see Section 6.5 for more details on the role of genres).

Of course, Figure 8 can give only a very crude picture, because it lumps together authors and works of very different types. In order to get a more detailed view of individual differences, sources which are comparable in terms of period and genre should be selected. Data for four groups that lend themselves to such comparisons, three of contemporary fiction writers and one of philosophers, are collected in Table 4:

Table 4: Comparison of authors from selected periods writing the same genre

\begin{tabular}{|c|c|c|c|c|c|}
\hline Author & $\begin{array}{l}\text { Dates of } \\
\text { Publications }\end{array}$ & $\begin{array}{l}\text { Number of } \\
\text { Words in } \\
\text { Source }\end{array}$ & $\begin{array}{l}\text { Number of } \\
\text { Occurrences } \\
\text { of } \mathrm{N}+\mathrm{BE}+\text { that }\end{array}$ & $\begin{array}{l}\text { Relative } \\
\text { Frequency } \\
\text { per Million } \\
\text { Words }\end{array}$ & $x^{2}$ Test Results \\
\hline \multicolumn{6}{|c|}{ Mid- $18^{\text {th }}$-Century Fiction } \\
\hline Richardson & $1740-1748$ & $1,406,495$ & 42 & 29.86 & \multirow{4}{*}{$\begin{array}{l}x^{2}=19.1447 \\
d f=3 \\
p=0.0002552\end{array}$} \\
\hline Fielding & $1742-1751$ & 691,821 & 33 & 47.70 & \\
\hline Haywood & $1744-1748$ & 170,858 & 7 & 40.97 & \\
\hline Smollett & $1748-1771$ & 659,690 & 5 & 7.58 & \\
\hline \multicolumn{6}{|c|}{ Early $19^{\text {th }}$-Century Fiction } \\
\hline Austen & $1795-1818$ & 887,680 & 71 & 79.98 & \multirow{3}{*}{$\begin{array}{l}x^{2}=12.7824 \\
d f=2 \\
p=0.001676\end{array}$} \\
\hline Shelley & $1818-1826$ & 250,729 & 11 & 43.87 & \\
\hline Scott & $1814-1820$ & 983,630 & 41 & 41.68 & \\
\hline
\end{tabular}




\begin{tabular}{|c|c|c|c|c|c|}
\hline Author & $\begin{array}{l}\text { Dates of } \\
\text { Publications }\end{array}$ & $\begin{array}{l}\text { Number of } \\
\text { Words in } \\
\text { Source }\end{array}$ & $\begin{array}{l}\text { Number of } \\
\text { Occurrences } \\
\text { of } \mathrm{N}+\mathrm{BE}+\text { that }\end{array}$ & $\begin{array}{l}\text { Relative } \\
\text { Frequency } \\
\text { per Million } \\
\text { Words }\end{array}$ & $\mathrm{X}^{2}$ Test Results \\
\hline \multicolumn{6}{|c|}{ Mid- $19^{\text {th }}$-Century Fiction } \\
\hline Brontë, E. & 1847 & 117,276 & 6 & 51.16 & \multirow{4}{*}{$\begin{array}{l}x^{2}=21.037 \\
d f=3 \\
p=0.0001034\end{array}$} \\
\hline Brontë, C. & $1847-1856$ & 395,351 & 12 & 27.82 & \\
\hline Dickens & $1836-1861$ & $1,409,404$ & 144 & 102.17 & \\
\hline Thackeray & $1848-1852$ & 491,855 & 50 & 101.66 & \\
\hline \multicolumn{6}{|c|}{ Late $18^{\text {th }}$-Century Philosophers } \\
\hline Hume & 1739-1779 & 137,954 & 6 & 43.49 & \multirow{3}{*}{$\begin{array}{l}x^{2}=58.3611 \\
d f=2 \\
p=2.124 e-13\end{array}$} \\
\hline Paine & $1776-1796$ & 179,138 & 48 & 267.95 & \\
\hline Burke & $1756-1796$ & $1,515,549$ & 129 & 85.12 & \\
\hline
\end{tabular}

In addition to authors' names, Table 4 renders dates of publications, overall numbers of words, numbers of attestations of the target construction, and normalized frequencies. Considerable differences can be observed in all four groups. Particularly extreme cases are the contrasts between Smollett and Fielding (7.58 vs. 47.70 occurrences per million words), and Hume and Paine (43.49 vs. 267.95), in both cases in texts of comparable extents $(137,954$ and 179,138 words respectively). The right-most column reports the results of chi-square tests which indicate that the differences are significant in all four groups. This demonstrates that even authors writing comparable types of texts around the same time differ significantly in terms of the frequency with which they use the construction.

In the terms of the predictions formulated above, this could be interpreted as indicating that symbolic associations connecting potential ideas to be encoded and the form $\mathrm{N}+\mathrm{BE}+$ that in production are not entrenched equally strongly in the minds of these authors. However, these differences in plain frequencies are of course a very crude measure of cotext-free entrenchment which would perhaps not even be worth reporting as such if they were not substantiated by the qualitative findings to be reported next. 


\subsection{Ranges of Nouns, Preferences for Nouns, Paradigmatic Relations, and Innovations}

In this section we are concerned with ways of judging the nature of schemas representing a 'construction' in a given author's mind. According to the ECModel, this can be done by looking at the following parameters:

- the range of nouns used in the construction, both in terms of different types of nouns as such and in terms of semantic classes;

- the distribution of tokens across types, indicating, among other things, preferences for certain nouns;

- paradigmatic relations between the nouns that are used and preferred by a given author;

- innovations, i.e. nouns that are not attested in the data before a given author's use, indicating the availability of a productive constructional schema that can be used to extend the potential of the construction.

The examination of our data along these parameters suggests a distinction into four basic types of author profiles. These are illustrated by typical examples in the following and summarized in Table 9.

The first type is exemplified by Edmund Burke (see Table 5), whose prolific writing contains 129 tokens of the construction spread across as many as 58 different nouns. This corresponds to a noun type-token ratio of 0.45 tokens per type, indicating considerable consolidation of tokens across type in spite of the large number of hapaxes. The rank list in terms of frequency rendered in Table 5 shows a strong preference for the noun fact. The epistemic modal noun truth and different types of factual nouns (e.g. causal: consequence, reason; neutral: thing; attitudinal: fault) further dominate the list, but mental (opinion, consolation) and linguistic nouns (objection, answer, charge) are found as well.

Table 5: Collocational range and usage preference for Edmund Burke

\begin{tabular}{ll}
\hline Tokens & Nouns \\
\hline 21 & fact \\
\hline 11 & opinion \\
\hline 8 & thing, consequence \\
\hline 6 & objection \\
\hline 4 & fault, reason, truth \\
\hline
\end{tabular}




\begin{tabular}{ll}
\hline Tokens & Nouns \\
\hline 3 & answer, substance \\
\hline 2 & $\begin{array}{l}\text { charge, condition, consolation, difference, effect, expression, principle, probability, } \\
\text { property }\end{array}$ \\
\hline 1 & $\begin{array}{l}\text { account, accusation, agreement, article, assertion, authority, circumstance, claim, } \\
\text { complaint, concern, confirmation, consideration, defence, dishonour, event, } \\
\text { evidence, fear, grievance, idea, issue, justification, limitation, maxim, mischief, } \\
\text { notion, object, opprobrium, order, part, plea, pleasure, point, proposal, purpose, } \\
\text { regulation, requisition, step, use, view }\end{array}$ \\
\hline
\end{tabular}

As far as paradigmatic relations are concerned, two semantic clusters of closely related nouns can be observed, namely fact and truth, and consequence, reason, and effect. Burke introduces three nouns into the construction which do not occur in our dataset before him, namely agreement, probability, and substance (cf. Table 3). Overall, this leaves the impression that Burke had a strongly entrenched high-level schema linking the form $\mathrm{N}+\mathrm{BE}+$ that to a range of meanings, particularly strongly to the expression of epistemic modality and factuality. The high frequency of the noun fact actually indicates that the epistemic meaning variant may have been available as a strong sub-schema.

The second type of profile is represented by Samuel Pepys (Table 6; see the examples in (13) below). His diary contains 30 tokens of the construction manifesting 13 types, which yields a noun type-token ratio very similar to that of Burke. Pepys' semantic range of nouns is much less wide than Burke's, however. He shows a very clear preference for linguistic nouns: as many as 17 of the 30 tokens instantiate the nouns news, talk, discourse, the three top-ranking nouns, as well as answer and piece of news. Despite this strong semantic focus on linguistic nouns, Pepys is on record in our database as the first user of the important noun fact (cf. Table 3) and the hapax expedient. We will come back to this finding in Section 7. Pepys' usage profile suggests that he does have a high-level schema licencing his two innovations, complemented by a strongly entrenched specific schema linking the form $\mathrm{N}+\mathrm{BE}+$ that to the meaning of reporting linguistic utterance and illocutionary acts (again see the examples rendered in (13) and the discussion in Sections 6.4 and 6.5 below). As will be shown below, the latter is supported by strong syntagmatic relations between the construction and selected nouns. 
Table 6: Collocational range and usage preference for Samuel Pepys

\begin{tabular}{ll}
\hline Tokens & Nouns \\
\hline 7 & news \\
\hline 4 & talk \\
\hline 3 & discourse, fear \\
\hline 2 & answer, reason, rule, thing \\
\hline 1 & business, expedient, fact, piece of news, truth \\
\hline
\end{tabular}

The third type, represented by Samuel Richardson (Table 7; examples in (14)), is essentially a variant of the second one. There is also a strong focus on a specific meaning variant of the construction, namely the encoding of states of emotion (fear, consolation, desire, hope, pleasure, etc.) and attitudes (misfortune, advantage, disgrace, excellence, etc.), but this focus is spread across a much wider range of nouns than in the case of Pepys. Paradigmatic associations and analogy seem to play an even greater role here. In addition, the overall range of nouns used by Richardson is wider, which is also reflected in a higher noun type-token ratio of 0.67. This suggests that Richardson's high-level schema was possibly a little stronger than Pepys', but one should not forget that the amount of material contributed by Richardson to our database is much more extensive than that by Pepys.

Table 7: Collocational range and usage preference for Samuel Richardson

\begin{tabular}{ll}
\hline Tokens & Nouns \\
\hline 4 & fear \\
\hline 3 & consolation, result \\
\hline 2 & comfort, condition, desire, hope, misfortune, pleasure, thing \\
\hline 1 & $\begin{array}{l}\text { advantage, concern, disgrace, doubt, end, excellence, felicity, improbability, intention, } \\
\text { mind, news, objection, occasion, opinion, point, trouble, truth, view }\end{array}$ \\
\hline
\end{tabular}

The fourth and final type is represented by Charlotte Brontë (Table 8). Contributing almost 400,000 words to the raw material, she nevertheless produces only 12 instances of our target construction. 
Table 8: Collocational range and usage preference for Charlotte Brontë

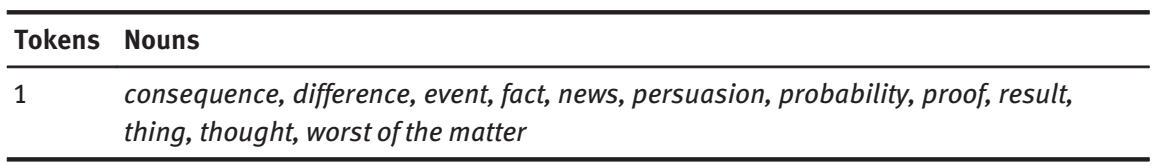

What is more, not a single one of the nouns she uses in the construction occurs twice, thus yielding a noun type-token ratio of 1 , which indicates that she has no collocational preferences. From a semantic point of view, her output makes up a fairly mixed bag of various factual nouns, as well as epistemic, linguistic, and mental ones. We interpret this as evidence for a weakly entrenched and extremely unspecific schema, which hardly manages to reach the level of activation required for frequent production. It is not surprising that just like Samuel Richardson, Charlotte Brontë is not responsible for an innovation in the nominal slot of the construction.

The four types and the profiles are summarized in Table 9. Brief glosses of the interpretation of the profiles in terms of entrenchment are included. Further authors belonging to the four classes are listed as well.

Table 9: Summary of the four types of schematization profiles

\begin{tabular}{|c|c|c|c|c|}
\hline & Type 1 & Type 2 & Type 3 & Type 4 \\
\hline Author & Burke & Pepys & Richardson & C. Brontë \\
\hline Words & $1,515,549$ & 367,747 & $1,406,495$ & 395,351 \\
\hline Range & very large & limited & large & limited \\
\hline Number of & 58 types & 13 types & 28 types & 12 types \\
\hline $\begin{array}{l}\text { Types and } \\
\text { Tokens }\end{array}$ & 129 tokens & 30 tokens & 42 tokens & 12 tokens \\
\hline $\begin{array}{l}\text { Noun Type- } \\
\text { Token Ratio }\end{array}$ & 0.45 & 0.43 & 0.67 & 1 \\
\hline $\begin{array}{l}\text { Semantic } \\
\text { Range }\end{array}$ & wide & $\begin{array}{l}\text { limited, } \\
\text { but one focus }\end{array}$ & $\begin{array}{l}\text { wide, } \\
\text { but one focus }\end{array}$ & $\begin{array}{l}\text { limited, } \\
\text { no focus }\end{array}$ \\
\hline $\begin{array}{l}\text { Paradigmatic } \\
\text { Clusters }\end{array}$ & $\begin{array}{l}\text { several, but not } \\
\text { very prominent }\end{array}$ & $\begin{array}{l}\text { one prominent } \\
\text { cluster: 'linguistic' }\end{array}$ & $\begin{array}{l}\text { one prominent } \\
\text { cluster: 'emotive/ } \\
\text { attitudinal' }\end{array}$ & no cluster \\
\hline Innovations & $\begin{array}{l}\text { agreement, prob- } \\
\text { ability, substance }\end{array}$ & fact, expedient & - & - \\
\hline
\end{tabular}




\begin{tabular}{|c|c|c|c|c|}
\hline & Type 1 & Type 2 & Type 3 & Type 4 \\
\hline Interpretation & $\begin{array}{l}\text { strong high-level } \\
\text { schema plus } \\
\text { several more } \\
\text { specific sub- } \\
\text { schemas }\end{array}$ & $\begin{array}{l}\text { possibly weak } \\
\text { high-level } \\
\text { schema, } \\
\text { strong sub- } \\
\text { schema ('linguis- } \\
\text { tic') }\end{array}$ & $\begin{array}{l}\text { weak high-level } \\
\text { schema, } \\
\text { strong sub- } \\
\text { schema ('emotive/ } \\
\text { attitudinal') }\end{array}$ & $\begin{array}{l}\text { weak high-level } \\
\text { schema }\end{array}$ \\
\hline $\begin{array}{l}\text { Further Authors } \\
\text { of this Type }\end{array}$ & $\begin{array}{l}\text { Austen } \\
\text { Chaucer } \\
\text { Dickens } \\
\text { Eliot } \\
\text { Johnson } \\
\text { Paine }\end{array}$ & $\begin{array}{l}\text { Berkeley } \\
\text { Boswell } \\
\text { Cromwell (letters) }\end{array}$ & $\begin{array}{l}\text { Painter } \\
\text { Johnson } \\
\text { Thackeray }\end{array}$ & $\begin{array}{l}\text { E. Brontë } \\
\text { Hobbes } \\
\text { Locke } \\
\text { Shakespeare } \\
\text { Shelley } \\
\text { Smollett } \\
\text { Walpole }\end{array}$ \\
\hline
\end{tabular}

Although the four types are of course idealizations across massive variation, most authors find a natural place in one of the four categories. Perhaps not surprisingly, the general trend is that authors that are particularly strongly represented in our data belong to Type 1, but there are also numerous exceptions: prolific writers such as Samuel Richardson, Tobias Smollett, and Charlotte Brontë, who nevertheless represent the other types, indicate that the allocation of authors to the four types is not just an artefact of the convenience-driven data-structure.

\subsection{Semi-Fixed Strings and Patterns}

The findings and interpretations reported in the previous section receive additional support by the analysis of semi-fixed strings.

To begin with, the different preferences of individual authors for certain nouns are also a sign of strong syntagmatic associations between the constructional schema and the nouns filling the variable slot: Burke's preference for fact and Pepys' preference for news are cases in point. Austen favours truth and consequence, but underuses, among others, fact, while Thackeray fills as many as 22 out of his 50 tokens of the construction with the two nouns truth and fact. This may seem trivial, given the fact that truth and fact are the most frequent types across centuries, but it turns out to be significant once we realize that as many as 110 out of the 139 authors that are identified as contributors to the database do not use the noun truth. We will come back to this observation in Section 7.

Some authors, especially those representing the schematization profiles of types 2 and 3 , show interesting semi-fixed patterns extending beyond the confines 
of the construction as such. In order to show this, we quote selected material from three authors: Pepys, Richardson, and Thomas Cromwell. The selection is determined by the goal to demonstrate patterns. Attestations by these authors that do not illustrate the respective patterns are omitted.

(13) Selected concordance lines from Pepys

therein. Here all the discourse is, that now the King is of opinion to have the Parliament depart the town. All the discourse now-a-day is, that the King will come again; and for all I see the reason of all this. The great discourse now is, that the Parliament shall be dissolved died the last week. All the news now is, that Sir Jeremy Smith is at Cales with

her part mighty well. All the news now is that Mr. Trevor is for certain to be Secretary which was made him. All the news from London is that things go on further towards a King.

to the office, where all the news this morning is that the Dutch are come with a fleet monk's soldiers. 4th. All the news to-day is, that the Parliament this morning voted the House gentleman. 27th. All the news this day is, that the Dutch are, with twenty-two sail of ships leave of him. But the best piece of newes is, that instead of a great many troublesome Lords

they must be purified. The worst news he tells me, is that Mr. Chetwind is dead and hath good rest. All the talk is that my Lord Sandwich hath perfected the peace which vexed me. The great talk is, that the Spaniards and the Hollanders do intend to set good night. 16th. The talk upon the 'Change is, that De Ruyter is dead, with fifty men

(14) Selected concordance lines from Richardson

to your honest friends: and all my pleasure is, that I can and will make you amends tribute to her memory. All my pleasure now is, that she knew not half my wicked pranks protection as I could find. All my comfort is, that your advice repeatedly given me to think so. All the comfort I know of in children, is, that when young they do with as you think fit in it. All my concern is, that this daring and foolish project, if carried on always been my principal care. All my fear is, that, when she comes to the point, let him say of me what he will. All my fear is, that, as he knows I am in disgrace of his lady.' And now, Belford, all my hope is, that this fellow (who attended us in her refusal to receive her. All her consolation is, that her unhappy situation is not owing to was no more? Her principal consolation, however, was, that she should not long to my corpse; in this case my desire is, that it may be interred in the churchyard think your going away a fault. The hope is, that things will still end happily, and

\section{(15) Selected concordance lines from Cromwell}

the Marches of Calays, the kinges pleasure is that ye and thother Commyssioners shall

the pleasure of his highnes is that the due dettes of the said howses well prouyde be enhabited, his graces pleasure is that your lordship shall cause some oone or two

The kinges pleasure is that you shal sende a spedy aunswer herof, remedy whereof the kinges graciouse pleasur is that ye shal cause the said persones

his gracious pleasure and commandment is that forasmoch as we hope herafter The kinges Maiestes pleasure is that you shal vieu his graces howse 
Kinges Maieste whose graciouse pleasure is that with all celerite ther shalbe the worst may be provided for, his graces pleasure is that it shalbe diligently forseen vnto youe, whiche myn advise and counsail is that youe shall in any wise ensue, that my poure and frendelie aduise is that his grace shall liberally wryte to the kinges maiestes will is that ye shal make the shortiest abode there ye can his gracious pleasure and commandment is that forasmoch as we hope chiefly myn advise and counsail is that youe shall in any wise ensue,

As shown in (13), Pepys shows a strong tendency to use his favoured linguistic nouns news, talk, and discourse in the schema all the $\mathrm{N}\left(\mathrm{Adv}_{\text {temporal }}\right)$ is that [...]. The meaning associated with this schema can roughly be glossed as 'rumors are that'. While the schema typical of Richardson (see 14) also includes the quantifier all, this is followed by the first-person possessive pronoun and an emotive noun. Richardson's use of this schema is associated with passages where his female protagonists talk or write about their emotions. Finally, Cromwell's use as shown in (15) is marked by the genitive King's preceding the directive illocutionary noun commandment, the volitive noun will or, most frequently, the emotive noun pleasure. Overall, the pronounced differences support the impression that the three authors rely on different variants of the constructional schema.

In terms of the framework described in Section 3, the repetition of such semifixed sequences of content and function words in and around the target construction can be interpreted as a result of the routinization of syntagmatic associations. Such usage patterns are particularly prominent in the writing of authors of types 2 and 3, who seem to have a strongly represented semantically specific sub-schema of the more general construction. These author-specific usage patterns provide an insight into the individual cognitive processes that contribute to the emergence of chunks, prefabs, and usage patterns on the macro-level of the speech community (cf. Bybee 2010: 33-56). In all three cases we can observe a combination of fixed chunks with some paradigmatically motivated variability. This would mean that alongside chunks the authors have access to a strongly entrenched and highly productive low-level schema, licencing variation in the nominal slot in spite of the strong syntagmatic association.

\subsection{Functions, Cotexts, and Context: Pragmatic Associations}

The concordance lines in the previous section provide excellent examples of the way in which the functions of uses of the ' $\mathrm{N}+\mathrm{BE}+$ that-construction' can motivate the emergence of usage patterns and schemas. Pepys' pattern is supported by the reporting function ('here is what people say'), Richardson's by the expressive function ('here is how I feel'), and Cromwell's by realizing the directive function 
by means of indirect illocutionary acts: the kinges pleasure or his graces pleasure can be glossed as 'this is what the King wants you to do'.

Differences with regard to preferences for certain functions can not only be observed in these usage patterns, however, but basically for all authors. These in turn seem to be influenced quite strongly by genres. Table 10 renders the distribution across functions for all 10 authors who produced 40 or more tokens of the construction.

Table 10: Author-specific distribution of functions (only authors with $n>40$ are included)

\begin{tabular}{|c|c|c|c|c|c|c|c|}
\hline & $\begin{array}{l}\text { Report- } \\
\text { ing }\end{array}$ & $\begin{array}{l}\text { Argumen- } \\
\text { tative }\end{array}$ & $\begin{array}{l}\text { Expla- } \\
\text { natory }\end{array}$ & Expressive & Directive & Opinative & Total \\
\hline \multicolumn{8}{|l|}{ Fiction } \\
\hline Richardson & $26 \%$ & $2 \%$ & $12 \%$ & $53 \%$ & & $7 \%$ & \\
\hline Austen & $44 \%$ & $21 \%$ & $17 \%$ & $15 \%$ & $1 \%$ & $1 \%$ & $100 \%$ \\
\hline Scott & $59 \%$ & $20 \%$ & $10 \%$ & $12 \%$ & & & $100 \%$ \\
\hline Dickens & $44 \%$ & $14 \%$ & $17 \%$ & $13 \%$ & $2 \%$ & $9 \%$ & $100 \%$ \\
\hline Thackeray & $42 \%$ & $40 \%$ & $12 \%$ & $2 \%$ & $2 \%$ & $2 \%$ & $100 \%$ \\
\hline Eliot & $47 \%$ & $13 \%$ & $20 \%$ & $13 \%$ & $2 \%$ & $5 \%$ & $100 \%$ \\
\hline \multicolumn{8}{|c|}{ Expository Writing } \\
\hline Johnson & $12 \%$ & $40 \%$ & $38 \%$ & $8 \%$ & & $2 \%$ & $100 \%$ \\
\hline Burke & $26 \%$ & $29 \%$ & $28 \%$ & $6 \%$ & $2 \%$ & $9 \%$ & $100 \%$ \\
\hline Paine & $23 \%$ & $27 \%$ & $35 \%$ & & & $15 \%$ & $100 \%$ \\
\hline \multicolumn{8}{|l|}{ History } \\
\hline Macaulay & $66 \%$ & & $32 \%$ & & & $2 \%$ & $100 \%$ \\
\hline
\end{tabular}

As the numbers for some intersections of AUTHOR X FUNCTION are very low, we do not see much sense in subjecting these data to inferential statistical procedures. A number of trends and outliers can be observed, however: not only the three authors of expository texts, Johnson, Paine, and Burke, but also Thackeray, who wrote fiction, share a relatively large proportion of uses serving the argumentative function. Not surprisingly, Macaulay, as the author of a history of England, stands out with the largest proportion of reporting uses, but Scott comes quite close to his score. Johnson, Burke, Paine, and Macaulay differ from the fiction authors with regard to the comparatively high proportion of explanatory uses. So preferences for certain functions can extend across genre boundaries. The reverse is also true: authors producing texts of the same genre do not necessarily share the 
same functional preferences. For example, a large proportion of Richardson's uses, as we have seen, is motivated by the expressive function, which in turn is, however, almost irrelevant for Thackeray.

We interpret all these differences and tendencies in terms of pragmatic associations which link genres, reasons for the production of a text, and functions of utterances to the activation of the construction. Topics are likely to play a role as well. Very simplistically speaking, when Pepys sits down to make an entry in his diary, and when he is about to record the rumours of the day, then the linguistic sub-schema of the ' $\mathrm{N}+\mathrm{BE}+$ that-construction' shows a particularly high activation potential and comes to his mind (see the concordance lines collected in (13) above). It is certainly remarkable that in as many as four of the concordance lines quoted in (13), his favourite expression stands at the very beginning of the entry for a fresh day. Likewise, when Richardson puts himself in the mind of his protagonists and plans to portray their emotions, utterances of the type my fear is or my concern is (see (14)) are readily activated.

That pragmatic associations influence the activation potential of sub-schemas of entrenched constructions can also be demonstrated by comparing the usage profiles of one author while writing different types of texts. Jane Austen can help to show this since our database includes both her novels and letters. Given that the corpus of Jane Austen's novels is of course much larger than that represented by her few remaining letters, it is not very surprising that 15 nouns that occur in her novels are not found in her letters. However, that the letters include 12 nouns used in the construction which are not found in the novels, namely account, anxiety, history, intention, meaning, message, occasion, opinion, reason, report, substance, and wish, is quite remarkable. It seems that the differences in terms of style, envisaged addressees, writing conditions, and topics activate nouns that do not make it to the surface in her fiction.

To wrap up this section, we think it is justified to conclude that individual differences between authors are much more pronounced than expected, not only between those writing different types of texts and/or writing in different periods, as could be expected, but also between authors that are very similar with regard to these parameters. The different parts of this section have demonstrated how these findings can be interpreted within the part of the EC-Model devoted to entrenchment processes. Implications of the findings for the link between entrenchment on the micro-level of individuals and conventionalization on the macro-level of the speech community will be discussed in the next section. 


\section{The Link between Entrenchment and Conventionalization}

To begin with, we would like to come back to the observation that Pepys contributes the first attestation of the noun fact. What is remarkable from the point of conventionalization is that the next occurrence of fact in our database is found as many as 73 years later in the work of Fielding. From this point onwards we find a massive increase in the use of fact. For the 50 years following Fielding's use in 1742 we have as many as 27 attestations of fact in our target construction. Of course it is likely that the noun was in use in the intermitting period, too; but if it happened to be true that it was not, then the reason why Pepys' innovation did not catch on at first could be that his diary was of course secret. Following the noun's first use in fiction by Fielding, its frequency of occurrence begins to rise. The fate of Pepys' favourite nouns news, talk and discourse support this idea. Talk and discourse are only used in the construction by Pepys, at least in our database. They remain hapaxes. As regards news, the first attestation of this noun in our data comes from Shakespeare's Richard III (1592). Shakespeare himself uses it a second time in The Tempest (1611). Overall, the noun is used 20 times between 1592 and 1866, with Pepys accounting for as many as 7 tokens. Neither news, nor for that matter talk and discourse, are exactly success stories. While these nouns were closely associated with the construction in Pepys' mind, there was no effect on the speech community, presumably because his secret diary could not contribute to the diffusion of these usage patterns in the speech community.

This observation on Pepys' favourite nouns belongs to the realm of speculative anecdotal evidence, of course. Unfortunately, even the 1,588 data points that we have collected are not sufficient for sound quantitative investigations. Only if the major writers of nineteenth-century fiction are lumped together, an opportunity, though a poor one, arises. Even if we focus on the most productive users of the construction, we are left with nouns which are used highly frequently by some authors and not at all by others. Keeping these reservations in mind we can interpret the data presented in Tables 11 and 12. Table 11 ranks the nouns that are used most frequently by five nineteenth-century fiction writers. 
Table 11: Comparison of frequencies of top-ranking collocates of $19^{\text {th }}$-century fiction authors (only authors with sufficiently large numbers of tokens)

\begin{tabular}{lcccccc}
\hline & Austen & Dickens & Eliot & Scott & Thackeray & Total \\
\hline truth & 10 & 9 & 1 & 9 & 12 & 41 \\
\hline fact & 3 & 13 & 3 & 4 & 10 & 33 \\
\hline consequence & 5 & 8 & 3 & 1 & 2 & 19 \\
\hline result & 3 & 8 & 2 & 1 & 0 & 15 \\
\hline thing & 1 & 9 & 2 & 0 & 13 \\
\hline opinion & 0 & 8 & 1 & 0 & 1 & 10 \\
\hline
\end{tabular}

Table 12 gives the results of pairwise correlations (Kendall's tau). Regarding the comparison between the five authors, only the correlations between Austen and Scott (0.64), Austen and Thackeray (0.50), and Dickens and Scott (0.48) are quite high, while all the others are low. Yet three out of the five authors - Austen, Scott, and Thackeray - show a strong correlation with the collective (consisting of the data of the other four authors), namely $0.78,0.83$, and 0.69 respectively.

Table 12: Kendall's tau: rank correlations among authors and between authors and collective

\begin{tabular}{lccrrrrr}
\hline & $\begin{array}{l}\text { Austen } \\
\text { (Fiction Only) }\end{array}$ & \multicolumn{2}{l}{$\begin{array}{l}\text { Dickens } \\
\text { (Fiction Only) }\end{array}$} & Eliot & Scott & Thackeray & $\begin{array}{l}\text { Sum Minus } \\
\text { Target Author }\end{array}$ \\
\hline Austen & & 0.16 & 0.23 & 0.64 & 0.50 & 0.78 \\
\hline Dickens & 0.16 & & 0.17 & 0.48 & 0.32 & 0.39 \\
\hline Eliot & 0.23 & 0.17 & & 0.08 & 0 & 0.30 \\
\hline Scott & 0.64 & 0.48 & 0.08 & & 0.50 & 0.83 \\
\hline Thackeray & 0.50 & 0.32 & 0 & 0.50 & & 0.69 \\
\hline $\begin{array}{l}\text { Sum Minus } \\
\text { Target Author }\end{array}$ & 0.78 & 0.39 & 0.30 & 0.83 & 0.69 & \\
\hline
\end{tabular}

This indicates that what Zimmerer, Cowell and Varley (2011) describe in the following quote could very well be quite common instead of being only a worstcase scenario: "in the worst case, group data describe a behavioral pattern that does not occur within a single individual” (Zimmerer, Cowell and Varley 2011: 492; cf. also Barlow 2013: 444). While this insight is to some extent predicted by the EC-Model, it suggests a new research agenda which requires a greater focus on the usage preferences and habits of individual authors and speakers and, more 
importantly, on the precise ways in which these habits conspire to structure and change grammar.

\section{Conclusion}

We have tried to show that historical corpus data can be used to investigate individual differences and that these differences can be interpreted in terms of different degrees and types of entrenchment. To come back to the question raised in Section 2, in light of his usage profile and in light of the differences to other authors, it seems likely that Pepys' utterance in (1) was licenced by the activation of a lexically-filled chunk resulting from repeated usage under similar pragmatic conditions. As this chunk still has internal variability - recall that analogous phrases such as all the discourse is that [...] are also attested - we can assume that the paradigmatic associations between the nouns in the nominal slot are not totally lost and that a sub-schema associating linguistic nouns to the constructional schema is also entrenched. While the usage profiles of other authors differ substantially, it was possible to classify them according to a number of parameters and allocate them to four different types. The comparison of the profiles of authors with similar characteristics with regard to period and genre suggested that there are strong inter-individual but less strong individual-to-collective differences. Although with 1,588 attestations, the database is quite substantial, it turned out that more data will be needed to investigate the nature of the links between individual authors and the collective and to show how the linguistic behaviour of authors affects change on the macro-level.

We hope that the separation between entrenchment and conventionalization processes has contributed to demonstrating the ultimate sources of many of the sub-processes traditionally regarded as being involved in language change. Analogy (cf., e.g., Hock 2003; Fischer 2011; Bybee 2015: ch. 5), as we have shown, begins to take shape in the minds of individual speakers on the basis of paradigmatic associations linking elements competing for occurrence in a syntagmatic sequence or a pragmatic frame. Analogy is thus first and foremost a cognitive process, and neither a linguistic nor a social one (Fischer 2011: 40-42). Likewise, chunking (Bybee 2010: 33-56, 2015: 238-239) starts out in individual minds rather than in speech communities and relies on the routinization of syntagmatic associations, often supported by pragmatic associations. The process of schematization, too, is genuinely cognitive in nature: since communication is the exchange of utterances and not the exchange of constructions, rules, or syntactic structures, the abstraction required for the formation of a schema must take place in individual minds (cf. Schmid 2015). Whether or not different speakers process the same 
utterance by activating the 'same' schema, whatever this could mean, is a different story. The nucleus of change by context-induced interpretations (Heine, Claudi and Hünnemeyer 1991: ch. 3) and invited inference (Traugott and Dasher 2004: 34-41) resides in the pragmatic associations carried over from multiple communicative events involving indirect interpretations, resulting in a consolidation of pragmatic associations into symbolic associations. Constructional changes triggered by newly incoming collocates have their source in the output of individual speakers. Whether these innovations catch on and spread in the speech community is again an entirely different issue on the level of conventionalization, as the large number of hapaxes in our database has shown. We consider it unlikely that other classic types of language change, e.g. bleaching or pragmaticalization, take place within the lifetime and linguistic history of individual speakers. Our impression is that for those processes to happen, a more long-term interaction between entrenchment and conventionalization processes seems to be required. Further research is required to address this issue.

Finally, should these findings and their interpretation be of interest to anybody who studies linguistic structures and language change proper, i.e. on the level of the linguistic system? One possible answer would be a clear no: the task of linguists is to search for the principles and rules that underlie grammar and the way in which they change over time; the performance of individual speakers has no role to play in this quest. If one agrees with this view, then one could still take home the message that beneath the surface of idealized speaker-hearers, individual variation is rampant. If one subscribes to a usage-based approach which assumes that grammars emerge from usage-events, then one would be well advised to take these insights more seriously, since from this perspective the usage patterns of individual speakers under specific pragmatic circumstances are likely to have an effect on grammar and the way in which it changes. If one believes that usage is at least co-determined by entrenchment, and that usage can therefore be used as a diagnostic of degrees and types of entrenchment, then one can read our paper as a methodological model for more research into individual differences using data from historical corpora.

\section{Works Cited}

\section{Corpora}

Austen $=$ Chapman, Robert William (ed.). 1881-1960. Jane Austen's Letters to her Sister Cassandra and Others. 2nd ed. 1952. London/New York: Oxford University Press. <http://ota.ox.ac. uk/desc/1520>. 
Project Gutenberg $=\langle$ https://www.gutenberg.org .

Helsinki = The Helsinki Corpus of English Texts. 1991. Compiled by Matti Rissanen (Project leader); Merja Kytö (Project secretary); Leena Kahlas-Tarkka, Matti Kilpiö (Old English); Saara Nevanlinna, Irma Taavitsainen (Middle English); Terttu Nevalainen, Helena RaumolinBrunberg (Early Modern English). Department of Modern Languages, Helsinki: University of Helsinki. 〈http://www.helsinki.fi/varieng/CoRD/corpora/HelsinkiCorpus〉.

OED3 = Oxford English Dictionary Online. 2000-. 3rd ed. online. Oxford: Oxford University Press. <http://www.oed.com>.

Old Bailey = Huber, Magnus, Magnus Nissel, Patrick Maiwald and Bianca Widlitzki (eds.). 2012. The Old Bailey Corpus. Spoken English in the 18th and 19th Centuries. Giessen: Giessen University. <www.uni-giessen.de/oldbaileycorpus〉.

Paston $=$ Gordon, Eric Valentine (ed.). 1953. Paston Letters and Papers of the Fifteenth Century. Oxford: Clarendon. <http://ota.ox.ac.uk/desc/1685>.

PCEEC $=$ Parsed Corpus of Early English Correspondence, parsed version. 2006. Annotated by Ann Taylor, Arja Nurmi, Anthony Warner, Susan Pintzuk, and Terttu Nevalainen. Compiled by the CEEC Project Team. York: University of York and Helsinki: University of Helsinki. <http://www.helsinki.fi/varieng/CoRD/corpora/CEEC/pceec.html〉.

Shakespeare $=\langle$ http: $/ /$ www.opensourceshakespeare.org $\rangle$.

\section{Secondary Sources}

Barlow, Michael. 2013. “Individual Differences and Usage-Based Grammar”. International Journal of Corpus Linguistics 18: 443-478.

Bybee, Joan. 2003. "Mechanisms of Change in Grammaticalization: The Role of Frequency". In: Brian D. Joseph and Richard D. Janda (eds.). Handbook of Historical Linguistics. Oxford: Blackwell. 602-623.

Bybee, Joan. 2010. Language, Usage and Cognition. Cambridge: Cambridge University Press. Bybee, Joan. 2015. Language Change. Cambridge: Cambridge University Press.

Cannon, Christopher. 2004. “Chaucer’s Style”. In: Piero Boitani and Jill Mann (eds.). The Cambridge Companion to Chaucer. Cambridge: Cambridge University Press. 233-250.

Craig, Hugh. 1992. "Authorial Styles and the Frequencies of Very Common Words: Jonson, Shakespeare, and the Additions to The Spanish Tragedy". Style 26: 199-220.

Craig, Hugh. 2002. “Common-Words Frequencies, Shakespeare's Style, and the Elegy by W. S.”. Early Modern Literary Studies: A Journal of Sixteenth-and Seventeenth-Century English Literature 8: 1-42.

Craig, Hugh. 2011. “Shakespeare's Vocabulary: Myth and Reality”. Shakespeare Quarterly 62: 53-74.

Diessel, Holger. 2007. "Frequency Effects in Language Acquisition, Language Use, and Diachronic Change". New Ideas in Psychology 25: 108-127.

Finegan, Eduard and Douglas Biber. 1995. "That and Zero Complementizers in Late Modern English: Exploring ARCHER from 1650-1990”. In: Bas Aarts and Charles F. Meyer (eds.). The Verb in Contemporary English. Cambridge: Cambridge University Press. 241-257.

Fischer, Olga. 2011. "Grammaticalization as Analogically Driven Change”. In: Heiko Narrog and Bernd Heine (eds.). The Oxford Handbook of Grammaticalization. Oxford: Oxford University Press. 31-42. 
Gries, Stefan and Martin Hilpert. 2012. “Variability-Based Neighbor Clustering: A Bottom-Up Approach to Periodization in Historical Linguistics”. In: Terttu Nevalainen and Elizabeth Closs Traugott (eds.). The Oxford Handbook on the History of English. Oxford: Oxford University Press. 134-144.

Givón, Talmy. 1990. Syntax: A Functional-Typological Introduction. Vol. 2. Amsterdam: Benjamins. Heine, Bernd, Ulrike Claudi and Friederike Hünnemeyer. 1991. Grammaticalization: A Conceptual Framework. Chicago, IL: University of Chicago Press.

Hilpert, Martin. 2013. Constructional Change in English: Developments in Allomorphy, Word Formation, and Syntax. Cambridge: Cambridge University Press.

Hock, Hans Henrich. 2003. “Analogical Change”. In: Brian D. Joseph and Richard D. Janda (eds.). Handbook of Historical Linguistics. Oxford: Blackwell. 441-460.

Horobin, Simon. 2007. Chaucer's Language. Basingstoke: Palgrave Macmillan.

Huber, Magnus. 2007. "The Old Bailey Proceedings, 1674-1834: Evaluating and Annotating a Corpus of 18th- and 19th-Century Spoken English”. In: Anneli Meurman-Solin and Arja Nurmi (eds.). Annotating Variation and Change. Helsinki: VARIENG. <http://www.helsinki.fi/varieng/series/volumes/01/huber/>.

Krug, Manfred. 2000. Emerging English Modals: A Corpus-Based Study of Grammaticalization. Berlin: Mouton de Gruyter.

Janda, Richard D. and Brian D. Joseph. 2003. “On Language, Change, and Language Change - or, of History, Linguistics, and Historical Linguistics”. In: Brian D. Joseph and Richard D. Janda (eds.). Handbook of Historical Linguistics. Oxford: Blackwell. 3-180.

Langacker, Ronald W. 1987. “Nouns and Verbs”. Language 63: 53-94.

Mantlik, Annette. 2011. The Historical Development of Shell Nouns: A Diachronic Study of Abstract Noun Constructions in English. Unpubl. PhD dissertation, Munich University.

Mantlik, Annette. 2013. “An Etymological Analysis of Shell Nouns”. In: Hans Sauer and Gaby Waxenberger (eds.). Recording English, Researching English, Transforming English. Frankfurt am Main: Lang. 133-161.

Mantlik, Annette and Hans-Jörg Schmid. forthcoming. "That-Complementizer Omission in $\mathrm{N}+\mathrm{BE}+$ that-Clauses - Register Variation or Constructional Change?”. In: Alex Ho-Cheong Leung and Wim van der Wurff (eds.). The Noun Phrase in English: Past and Present. Amsterdam: Benjamins.

Raumolin-Brunberg, Helena and Arja Nurmi. 2011. "Grammaticalization and Language Change in the Individual”. In: Heiko Narrog and Bernd Heine (eds.). The Oxford Handbook of Grammaticalization. Oxford: Oxford University Press. 251-262.

Rissanen, Matti. 1991. “On the History of that/Zero as Clause Object Links in English”. In: Karin Aijmer and Bengt Altenberg (eds.). English Corpus Linguistics: Studies in Honour of Jan Svartvik. London: Longman. 272-289.

Rohdenburg, Günter. 2013. “Using the OED Quotations Database as a Diachronic Corpus”. In: Manfred Krug and Julia Schlüter (eds.). Research Methods in Language Change and Variation. Cambridge: Cambridge University Press. 136-157.

Schmid, Hans-Jörg. 2000. English Abstract Nouns as Conceptual Shells: From Corpus to Cognition. Berlin/New York: Mouton de Gruyter.

Schmid, Hans-Jörg. 2013. "Is Usage more than Usage After All? The Case of English not that". Linguistics 51: 75-116.

Schmid, Hans-Jörg. 2014a. "Lexico-Grammatical Patterns, Pragmatic Associations and Discourse Frequency”. In: Thomas Herbst, Hans-Jörg Schmid and Susen Faulhaber (eds.). Constructions - Collocations - Patterns. Berlin: Mouton de Gruyter. 239-293. 
Schmid, Hans-Jörg. 2014b. "A Framework for Understanding Linguistic Entrenchment and its Psychological Foundations in Memory and Automatization". <http://www.anglistik.unimuenchen.de/personen/professoren/schmid/schmid_publ/entrenchment-intro.pdf>; accessed 30 April 2015. [To appear in: Hans-Jörg Schmid (ed.). Entrenchment, Memory and Automaticity: The Psychology of Linguistic Knowledge and Language Learning. Boston, MA: APA and Walter de Gruyter.]

Schmid, Hans-Jörg. 2015. “A Blueprint of the Entrenchment-and-Conventionalization Model”. Yearbook of the German Cognitive Linguistic Association 3: 5-27.

Taavitsainen, Irma. 1995. "Narrative Patterns of Affect in Four Genres of the Canterbury Tales". The Chaucer Review: A Journal of Medieval Studies and Literary Criticism 30: 191-210.

Traugott, Elizabeth Closs and Richard Dasher. 2004. Regularity in Semantic Change. Cambridge: Cambridge University Press.

Traugott, Elizabeth Closs and Graeme Trousdale. 2013. Constructionalization and Constructional Change. Oxford: Oxford University Press.

Zimmerer, Vitor, Patricia Cowell and Rosemary Varley. 2011. “Individual Behavior in Learning of an Artificial Grammar”. Memory and Cognition 39: 491-501. 